\title{
GALLIUM ARSENIDE P-I-N DETECTORS FOR HIGH-SENSITIVITY IMAGING OF THERMAL NEUTRONS
}

\author{
Contract Period \\ 2 September 1998 through 17 March 1999
}

Submitted under:

Contract No. DE-FG02-98ER82672

Submitted to:

Tanga R. Baylor

U.S. Department of Energy/ACQ

9800 South Cass Avenue, Argonne, IL 60439

Prepared by:

Stanley M. Vernon

Submitted by:

Spire Corporation

One Patriots Park

Bedford, MA 01730-2396

SBIR RIGHTS NOTICE (JUN 1987) - These SBIR data are furnished with SBIR rights under Grant No. DE-FG02-97ER82480. For a period of 4 years after acceptance of all items to be delivered under this grant, the Government agrees to use these data for Government purposes only, and they shall not be disclosed outside the Government (including disclosure for procurement purposes) during such period without permission of the grantee, except that, subject to the foregoing use and disclosure prohibitions, such data may be disclosed for use by support contractors. After the aforesaid 4-year period the Government has a royalty-free license to use and to authorize others to use on its behalf, these data for Government purposes, but is relieved of all disclosure prohibitions and assumes no liability for unauthorized use of these data by third parties. This Notice shall be affixed to any reproductions of these data in whole or in part.

NOTICE: This report was prepared as an account of work sponsored by the United States Government. Neither the United States nor the United States Department of Energy, nor any of their employees, nor any of their awardees, subcontractors, or their employees, makes any warranty, express or implied, or assumes any legal liability or responsibility for the accuracy, completeness, or usefulness of any information, apparatus, product or process disclosed or represents that its use would not infringe privately-owned rights. 


\section{DISCLAIMER}

This report was prepared as an account of work sponsored by an agency of the United States Government. Neither the United States Government nor any agency thereof, nor any of their employees, make any warranty, express or implied, or assumes any legal liability or responsibility for the accuracy, completeness, or usefulness of any information, apparatus, product, or process disclosed, or represents that its use would not infringe privately owned rights. Reference herein to any specific commercial product, process, or service by trade name, trademark, manufacturer, or otherwise does not necessarily constitute or imply its endorsement, recommendation, or favoring by the United States Government or any agency thereof. The views and opinions of authors expressed herein do not necessarily state or reflect those of the United States Government or any agency thereof. 


\section{DISCLAIMER}

Portions of this document may be illegible in electronic image products. Images are produced from the best available original document. 


\section{PROJECT SUMMARY}

This SBIR Phase I developed neutron detectors made from gallium arsenide (GaAs) ptype/ intrinsic/n-type (P-I-N) diodes grown by metalorganic chemical vapor deposition (MOCVD) onto semi-insulating (SI) bulk GaAs wafers. A layer of isotopically enriched boron10 evaporated onto the front surface serves to convert incoming neutrons into lithium ions and a $1.47 \mathrm{MeV}$ alpha particle which creates electron-hole pairs that are detected by the GaAs diode. Various thicknesses of "intrinsic" (I) undoped GaAs were tested, as was use of a back-surface field (BSF) formed from a layer of $\mathrm{Al}_{x} \mathrm{Ga}_{1-x}$ As. Schottky-barrier diodes formed from the same structures without the $\mathrm{p}+\mathrm{GaAs}$ top layer were tested as a comparison.

After mesa etching and application of contacts, devices were tested in visible light before application of the boron coating. Internal quantum efficiency (IQE) of the best diode near the GaAs bandedge is over $90 \%$. The lowest dark current measured is $1 \times 10^{-12}$ amps at $-1 \mathrm{~V}$ on a $3 \mathrm{~mm} \times 3 \mathrm{~mm}$ diode, or a density of $1.1 \times 10^{-11} \mathrm{amps} \mathrm{cm}^{-2}$, with many of the diode structures tested having nearly similar results. The PIN diodes were significantly better than the Schottky barrier device, which had six orders of magnitude higher dark current.

Diodes were characterized in terms of their current-mode response to $5.5 \mathrm{MeV}$ alpha particles from 241-Americium. These radiation-induced currents were as high as $9.78 \times 10^{-7} \mathrm{~A}$ $\mathrm{cm}^{-2}$ on a PIN device with an $\mathrm{Al}_{\mathrm{x}} \mathrm{Ga}_{1-\mathrm{x}} \mathrm{As}$ BSF. Simple PIN diodes had currents as high as $2.44 \mathrm{x}$ $10^{-7} \mathrm{~A} \mathrm{~cm}^{-2}$, with thicker undoped layers showing better sensitivity.

Boron coatings were applied, and response to neutrons tested at University of Michigan by Dr. Doug McGregor. Devices with PIN and Schottky barrier designs showed neutron detection efficiencies as high as $2 \%$ on $5 \mu \mathrm{m}$ thick devices, with no need for external bias voltages. PIN diodes showed higher breakdown voltages and lower noise characteristics than did the Schottky barrier design. Uniformity of device operation across the wafer was excellent, indicating that multi-pixel array fabrication should be straightforward.

Phase II plans include diode optimization, further exploration of the BSF effect, optimization of the fabrication process, and development and testing of multi-element arrays. 


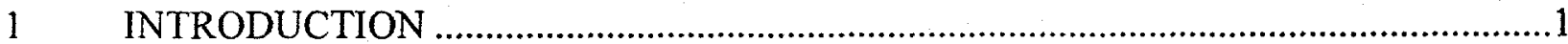

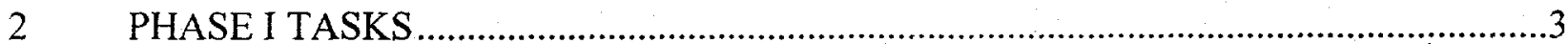

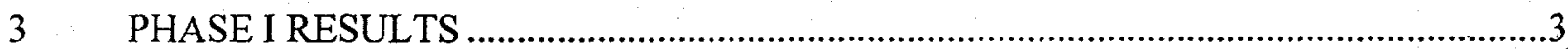

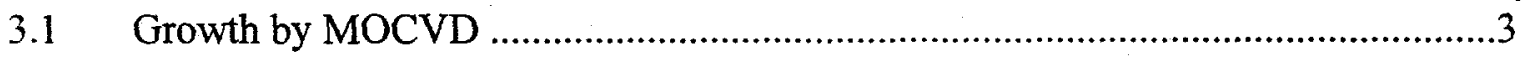

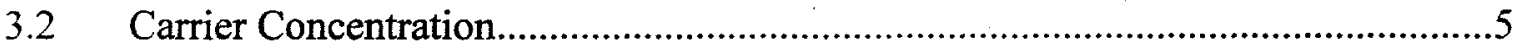

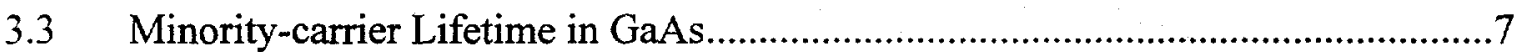

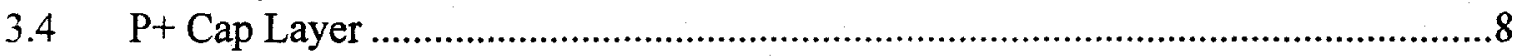

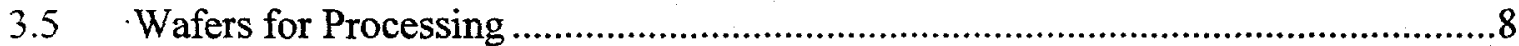

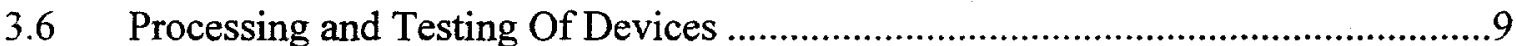

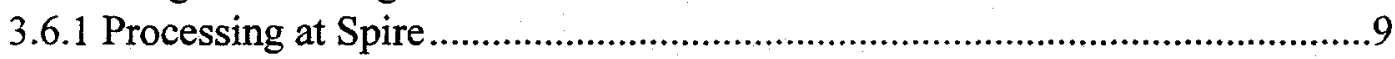

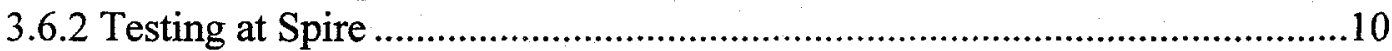

3.6.3 Testing of Response to Alpha Particles ........................................................14

3.7.1 Processing at University of Michigan - Deposition of Boron-10 ................19

3.7.2 Radiation Testing at University of Michigan.................................................20

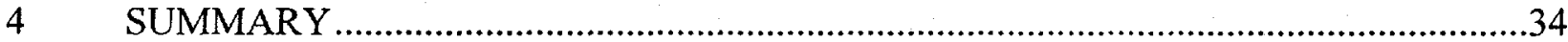

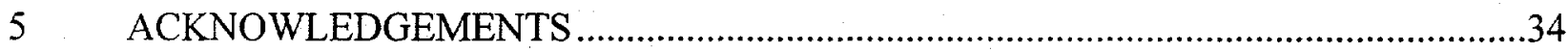

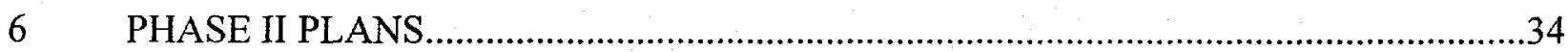

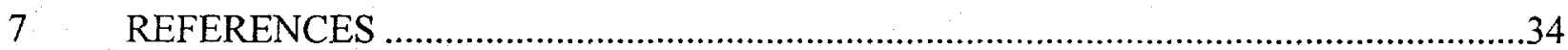




\section{LIST OF FIGURES}

Page

1 Cross-sectional view of epitaxial GaAs neutron detector

2 3-dimensional view showing layout of the surface features for the GaAs PIN diode neutron detector

3 Schematic drawing of the "400-S" MOCVD reactor used in this work.

4 Polaron ${ }^{\mathrm{TM}}$ profile of sample number M3-3229, undoped GaAs, $\approx 6 \mu \mathrm{m}$ thick, grown at $675^{\circ} \mathrm{C}, \mathrm{V}$-III $=86$

5 Polaron ${ }^{\mathrm{TM}}$ profile of sample number M3-3230, undoped $\mathrm{GaAs}, \approx 6 \mu \mathrm{m}$ thick, grown at $675^{\circ} \mathrm{C}, \mathrm{V}$-III $=172$

6 Room-temperature photoluminescence data for sample M3-3229, undoped GaAs, $\approx 6$ $\mu \mathrm{m}$ thick, grown at $675^{\circ} \mathrm{C}, \mathrm{V}-\mathrm{III}=86$.

7 Schematic of wafer number M3-3247, with $\mathrm{Al}_{\mathrm{x}} \mathrm{Ga}_{1-\mathrm{x}} \mathrm{As}$ back-surface field ..........................9

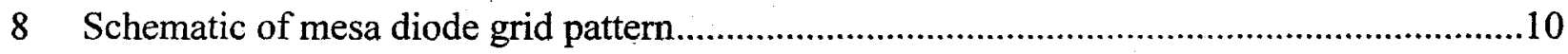

9 Measured current-voltage data for the nine diodes (eight PINs, and one SB .....................11

10 Measured internal quantum efficiency data $(400-900 \mathrm{~nm})$ for the nine diodes of Figure 9

11 Measured external quantum efficiency data $(400-900 \mathrm{~nm})$ for the nine diodes of Figure 9

12 Measured response of the six structure to alpha particles from the 241-Am source.............16

13 Measured dark-current data for the six test diodes of Figure 12 ..................................17

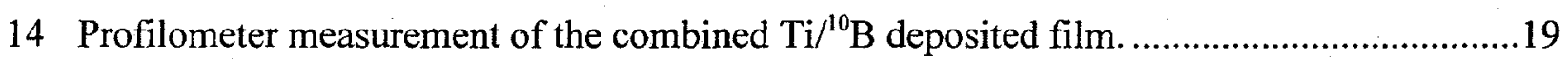

15 Basic scheme of a boron coated semiconductor neutron detector ....................................21

16 Reaction products given off from a thermal neutron interaction in the ${ }^{10} \mathrm{~B}$ film are emitted isotropically

17 The reaction products have different energies and masses, resulting in different ranges within the neutron reactive film.

18 The Bragg ionization distributions in pure ${ }^{10} \mathrm{~B}$ for charged particles emitted from the ${ }^{10} \mathrm{~B}(\mathrm{n}, \alpha){ }^{7} \mathrm{Li}$ reaction

19 Energy retained by charged particles emitted from the ${ }^{10} \mathrm{~B}(\mathrm{n}, \alpha)^{7} \mathrm{Li}$ reaction that enter the GaAs detector orthogonally as a function of interaction location distance from the detector contact interface. Negligible charged particle energy loss in the contact was assumed for the calculation.

20 The thermal neutron flux will decrease as it becomes absorbed in the ${ }^{10} \mathrm{~B}$ film..... 


\section{LIST OF FIGURES (concluded)}

21 The calculated efficiency contributions of each reaction product particle and the total thermal neutron detection efficiency as a function of the ${ }^{10} \mathrm{~B}$ film thickness.

22 The experimental arrangement used to test the ${ }^{10} \mathrm{~B} / \mathrm{GaAs}$ detectors with thermal neutrons

23 Bragg ionization distributions for charge particles transiting a ${ }^{10} \mathrm{~B} / \mathrm{GaAs}$ device with $6500 \AA$ of ${ }^{10} \mathrm{~B}$, and a $2000 \AA \mathrm{p}+\mathrm{GaAs}$ blocking contact layer.

24 Bragg ionization distributions for charge particles transiting a ${ }^{10} \mathrm{~B} / \mathrm{GaAs}$ device with $6500 \AA$ of ${ }^{10} \mathrm{~B}$, and a thin Schottky contact layer.

25 The reaction product spectrum from thermal neutron interactions in ${ }^{10} \mathrm{~B} / \mathrm{GaAs}$ detector S3242-3

26 The reaction product spectrum from thermal neutron interactions in ${ }^{10} \mathrm{~B} / \mathrm{GaAs}$ detector S3243-1

27 The reaction product spectrum from thermal neutron interactions in ${ }^{10} \mathrm{~B} / \mathrm{GaAs}$ detector S3278-1 


\section{LIST OF TABLES}

Page

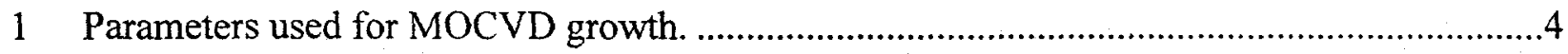

2 Wafers grown for device processing. Bold indicates wafers actually coated with boron at University of Michigan. .9

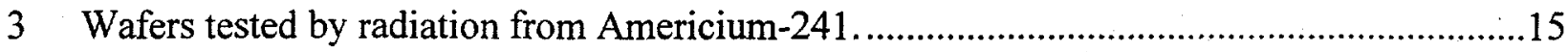

4 Measured dark currents and response to alpha particles....................................................18 


\section{INTRODUCTION}

Basic Idea Proposed - Neutron detectors are important for many applications, including energy exploration, personnel and environmental safety, treaty verification, reactor control, medicine, and detection of illicit materials.

Of the many possible neutron detectors available, boron-coated GaAs-based diodes offer advantages including small size, light weight, room-temperature operation, high signal-to-noise ratio, good energy resolution, and low-voltage operation. However, higher performance levels are needed to make GaAs neutron detectors useful for a wide variety of important applications

Areas needing improvements over existing GaAs devices include increased chargecollection efficiency, reduced noise level, reduced bias, increased radiation tolerance, and to make the fabrication process as high-yield and reliable as possible. The GaAs epitaxial PINjunction-diode detector offers potential advantages in all these issues, as explained later in this section.

Schottky-barrier (SB) GaAs detectors, with boron-10 absorber layers, fabricated on bulk semi-insulating (SI) wafers, have demonstrated energy resolution better than $2.5 \%$ and chargecollection efficiency (CCE) above $80 \%$ for $5.5 \mathrm{MeV}$ alpha particles ${ }^{1-3}$ indicating the ability of such devices to discern between high-energy charged-particle interactions and background gamma-ray events. This Phase I effort focussed on developing the configuration shown in Figures 1 and 2. The device geometry shown in Figure 2 is most useful in an array configuration. A simpler design was actually tested in Phase I, as explained in section 3.6.1

The basic device operation of this detector is that a thermal neutron, absorbed in the boron-10 layer, usually ( $94 \%$ of the time) generates an $840 \mathrm{keV}$ lithium ion and a $1.47 \mathrm{MeV}$ alpha particle. The alpha particle has a range of nearly $5 \mu \mathrm{m}$ in GaAs. As the alpha particle moves through GaAs it creates electron-hole pairs. These pairs are efficiently collected if the GaAs region in which they are generated is the depletion region of a Schottky-barrier or PN junction. In the configuration of Figure 1, the P+-to-undoped interface is the junction at which carriers are collected. The intrinsic (I) GaAs layer is actually slightly $\mathrm{N}$ type, due to an unavoidable background carrier concentration $\left(\geq 10^{13}\right.$ electrons $\left.\mathrm{cm}^{-3}\right)$. Since this layer is "intrinsic" (or unintentionally doped), but actually slightly $\mathrm{N}$ type, the structure shown above is, therefore, referred to as both a P-N junction or a P-I-N junction.

In this scheme, the undoped GaAs layer has a thickness between 1 and $5 \mu \mathrm{m}$; to become fully depleted, the applied bias is between about zero and $25 \mathrm{~V}$, depending upon the actual carrier concentration achieved. The P+ GaAs is $\approx 2000 \AA$ thick, doped $\approx 1 \times 10^{19} \mathrm{~cm}^{-3}$ (to insure low resistivity), and which does not cause any appreciable absorption of charged particles from the boron layer. 


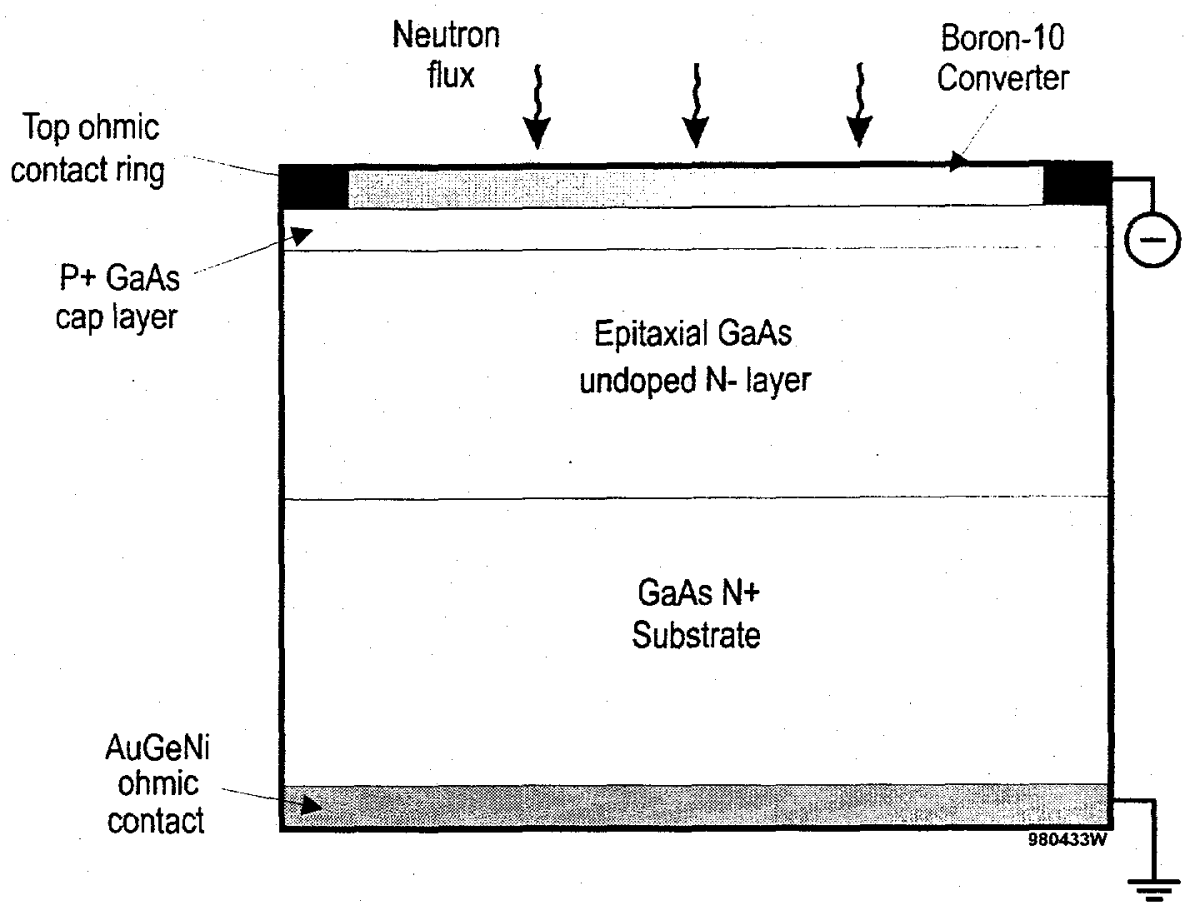

Figure 1 Cross-sectional view of epitaxial GaAs neutron detector.

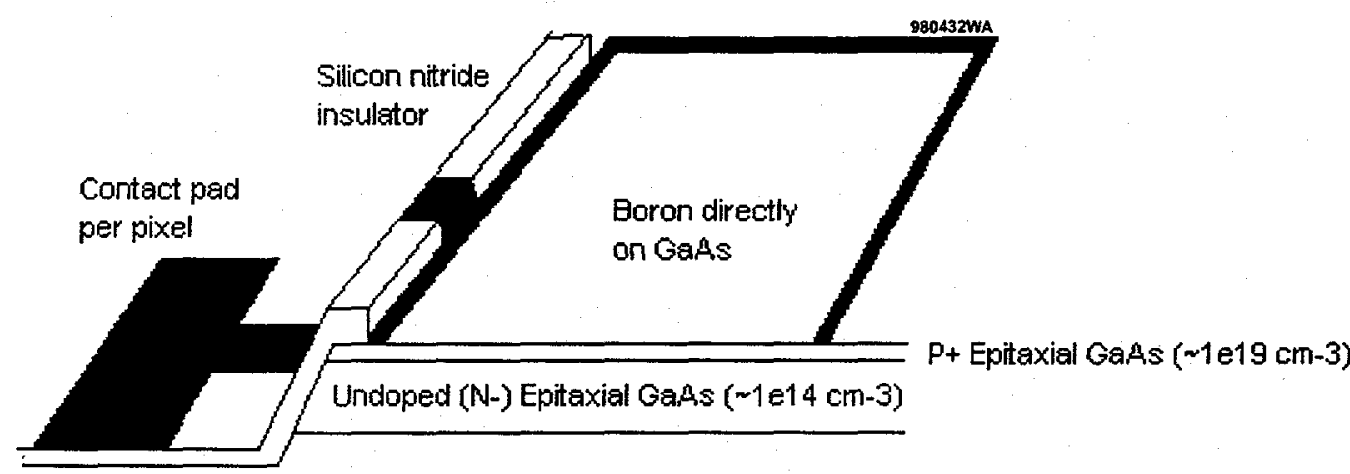

$N+$ GaAs wafer $(\sim 3 e 18 \mathrm{~cm}-3)$

AuGeNi Ohmic Contact (common to all pixels)

Figure 2 3-dimensional view showing layout of the surface features for the GaAs PIN diode neutron detector. The detector area is $1 \mathrm{~mm} \times 1 \mathrm{~mm}$, and the contact pad is $0.1 \mathrm{~mm} \times$ $0.1 \mathrm{~mm}$. 
An advantage of the ring-contact PIN configuration shown here is that the reaction products from the boron-neutron interaction are emitted directly into the GaAs, with no losses due to absorption in an interfacial metal layer inherent in a Schottky-barrier design. Figure 2 shows that pixel diodes are fabricated as mesas, with silicon nitride insulating areas between. The contact pads are small enough to allow for fairly close packing of the pixels in an array. Having the small contact pad on top of the pixel (covering only $1 \%$ area) is another possibility for future integration schemes, depending upon exact system specifications.

Although the design proposed is shown in Figure 2, which would be quite useful in an array configuration, for this Phase I, a simpler design was fabricated and tested, as explained in Section 3.6.

\section{PHASE I TASKS}

The tasks proposed for Phase I study include the following:

- Design epitaxial GaAs diode structures for efficient neutron detection

- Using epitaxially grown layers of high-purity GaAs (N less than $\approx 5 \times 10^{14} \mathrm{~cm}^{3}$ ), grow both a PIN structure and an undoped GaAs layer suitable for Schottky-barrier fabrication.

- Explore the usefulness of an AlxGa1-xAs back-surface field layer

- Characterize the GaAs diode structures

- Design the fabrication process and mask-set needed to make neutron detector diodes from these epitaxial wafers

- Fabricate both Schottky-barrier and PIN-diode neutron detectors on MOCVDgrown wafers

- Test these diodes for neutron detector operation

All tasks were successfully completed; results are detailed in the following sections.

\section{PHASE I RESULTS}

\subsection{Growth by MOCVD}

The GaAs PIN structures grown in this work were deposited by metalorganic chemical vapor deposition (MOCVD). This technique forms epitaxial GaAs films by reacting a gaseous arsenic source, arsine $\left(\mathrm{AsH}_{3}\right)$ with $\mathrm{Ga}$ vapors derived from the metalorganic liquid source, trimethylgallium (TMGa), at a high temperature (around $700^{\circ} \mathrm{C}$ ) to form a thin film of GaAs. The MOCVD reactor used for this process is shown schematically in Figure 3 This system can deposit on one 4-inch diameter wafer per batch. Excellent uniformity of thickness across the 4" wafer (standard thickness deviation less than 1\%) is routinely achieved. 

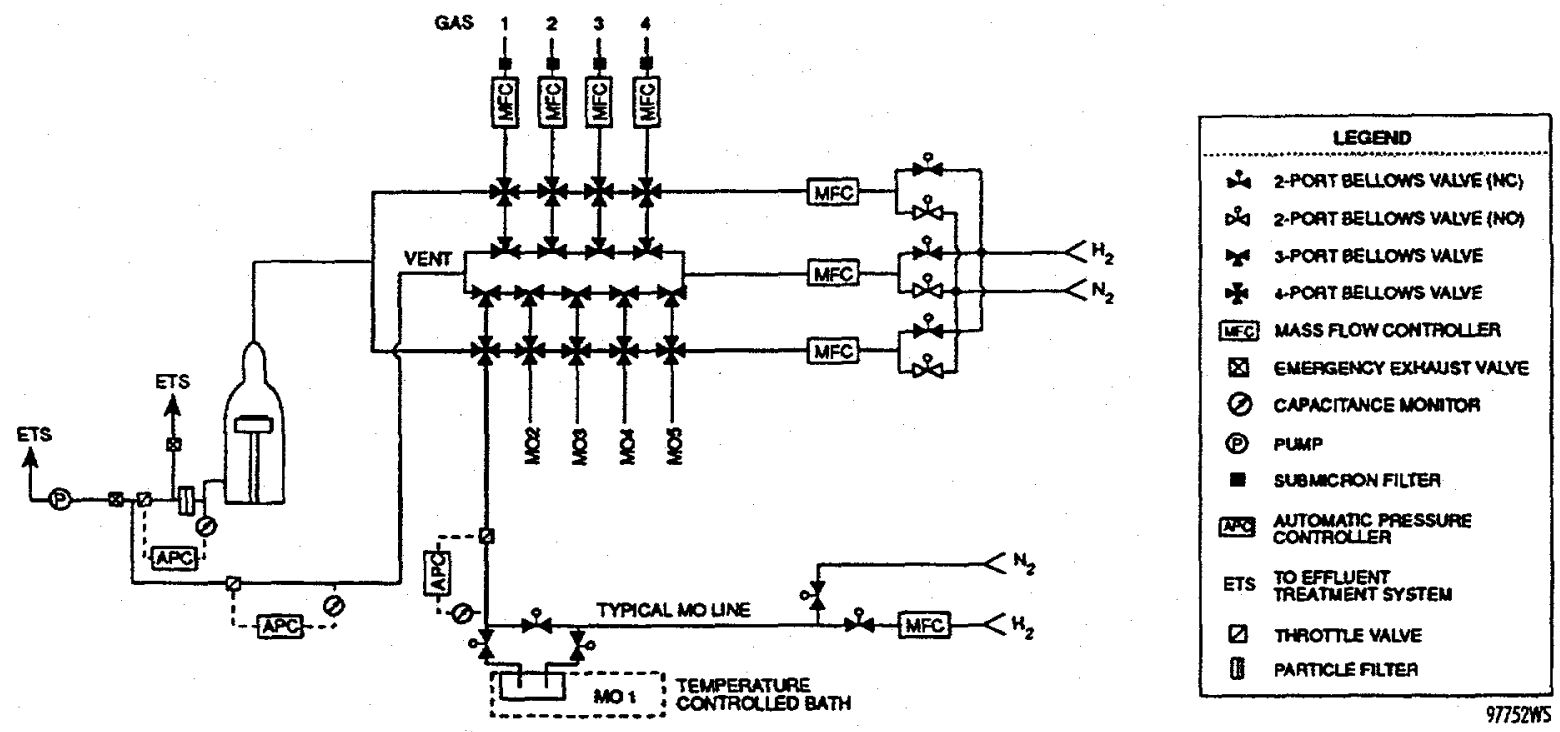

Figure 3 Schematic drawing of the "400-S" MOCVD reactor used in this work.

Growth parameters tested for GaAs and $\mathrm{Al}_{\mathrm{x}} \mathrm{Ga}_{1-\mathrm{x}} \mathrm{As}$ in Phase I are shown in Table 1.

Table $1 \quad$ Parameters used for MOCVD growth.

\begin{tabular}{|c|c|}
\hline PARAMETER & VALUE \\
\hline MOCVD REACTOR & SPI-MOCVD 400-S \\
\hline CAPACITY & One 4" wafer \\
\hline GROWTH TEMPERATURE $\left({ }^{\circ} \mathrm{C}\right)$ & $\begin{array}{l}600-675 \text { for } \mathrm{GaAs} \\
675-725 \text { for } \mathrm{Al}_{x} \mathrm{Ga}_{1-x} \mathrm{As}\end{array}$ \\
\hline GROWTH RATE & $\begin{array}{l}10 \AA / \sec \text { for } \mathrm{GaAs} \\
4-16 \AA / \mathrm{sec} \text { for } \mathrm{Al}_{\mathrm{x}} \mathrm{Ga}_{1-x} \text { As }\end{array}$ \\
\hline SOURCES & $\begin{array}{l}\text { trimethylgallium (TMGa) } \\
\text { triethylgallium (TEGa) } \\
\text { trimethylaluminum (TMAl) } \\
\text { arsine }\left(\mathrm{AsH}_{3}\right)\end{array}$ \\
\hline P-TYPE DOPANT & carbon-tetrabromide $\left(\mathrm{CBr}_{4}\right)$ \\
\hline V-III RATIO & $\begin{array}{l}25-172 \text { for } \mathrm{GaAs} \\
60-140 \text { for } \mathrm{Al}_{\mathrm{x}} \mathrm{Ga}_{1-\mathrm{x}} \mathrm{As}\end{array}$ \\
\hline
\end{tabular}

We first worked on getting the undoped GaAs to have the lowest possible carrier concentration, largest depletion depth, highest mobility, and good surface morphology. We grew test films of undoped GaAs, either 6 or $10 \mu \mathrm{m}$ thick, on GaAs substrates that were semi-insulating (SI) or highly doped $\mathrm{n}$ type $(\mathrm{N}+)$. Characterization was done with Hall-effect measurements, at room temperature $(300 \mathrm{~K})$ or liquid helium temperature $(77 \mathrm{~K})$, from which we could get average carrier concentration and mobility, and by electrochemical capacitance-voltage (CV) profiling using the Polaron TM Plotter (made by Biorad Corporation) to get a plot of carrier concentration versus depth. This showed us the doping level, carrier type, and the zero-bias depletion depth. 
When using very pure source chemicals for MOCVD growth of GaAs, the background carrier concentration in unintentionally doped films depends strongly on the V-III ratio (which here is the arsenic-to-gallium ratio) and growth temperature. These can be varied, but within the constraints of getting good surface quality and good transport properties. We used our twenty years of experience to quickly arrive at growth parameters which yielded excellent films.

\subsection{Carrier Concentration}

Experiments started by growing GaAs at $600^{\circ} \mathrm{C}$, at a V-III ratio of 25 or 86 . These runs at $600^{\circ} \mathrm{C}$ yielded hazy surface quality, but Polaron-measured carrier concentration of only $6 \times 10^{14} \mathrm{~cm}^{-3}$, with a depletion depth at least $3 \mu \mathrm{m}$. Room-temperature Hall data for the best film of this group showed n-type conductivity, at a level of $6 \times 10^{14} \mathrm{~cm}^{-3}$, with poor mobility $\left(\leq 2600 \mathrm{~cm}^{2} / \mathrm{V}-\mathrm{sec}\right)$. The poor surface and low mobility caused us to then look at highertemperature growths.

Improvements were made by using a growth temperature of $620^{\circ} \mathrm{C}$, at a V-III ratio of 86 . The surfaces were now better, with Polaron readings as low as $2 \times 10^{14} \mathrm{~cm}^{-3}$, depletion depths of 1-4 $\mu \mathrm{m}$, and Hall data that showed $\mathrm{n} \approx 7 \times 10^{14} \mathrm{~cm}^{-3}$ and mobility of $\leq 4800 \mathrm{~cm}^{2} / \mathrm{V}$-sec. Of several runs at $620^{\circ} \mathrm{C}$, results varied widely, so other conditions were explored.

Growth at $650^{\circ} \mathrm{C}$, V-III $=86$ gave excellent surfaces, with Polaron readings around $3 \times 10^{14} \mathrm{~cm}^{-3}$ and depletion depths of $1-3 \mu \mathrm{m}$, and Hall results that showed $\mathrm{n} \approx 1 \times 10^{15} \mathrm{~cm}^{-3}$, mobility $\approx 5000 \mathrm{~cm}^{2} / \mathrm{V}$-sec. Conditions for growing better undoped layers were still sought.

Growing undoped GaAs at $675^{\circ} \mathrm{C}$ gave our best results. At a V-III ratio of 86 , Polaron results showed $\mathrm{n}$ as low as $6 \times 10^{13} \mathrm{~cm}^{-3}$, and depletion depths up to $6 \mu \mathrm{m}$. A typical Polaron measurement is shown in Figure 4. Hall data on these films showed $\mathrm{n} \approx 3 \times 10^{14} \mathrm{~cm}^{-3}$, but fair mobility values, around $4000 \mathrm{~cm}^{2} / \mathrm{V}$-sec $\left(77 \mathrm{~K}\right.$ Hall $\approx 20,000 \mathrm{~cm}^{2} / \mathrm{V}$-sec). The V-III ratio was then doubled (to 172); these films showed much improved mobility, as high as $6700 \mathrm{~cm}^{2} / \mathrm{V}-\mathrm{sec}$, ( $77 \mathrm{~K}$ Hall mobility of $85,000 \mathrm{~cm}^{2} / \mathrm{V}-\mathrm{sec}$ ) with $\mathrm{n}$ (by Hall) still $\approx 3 \times 10^{14} \mathrm{~cm}^{-3}$. Polaron on these also showed $\mathrm{n} \approx 3 \times 10^{14} \mathrm{~cm}^{-3}$, but a depletion depth $\leq 2 \mu \mathrm{m}$. A Polaron measurement of such a sample is shown in Figure 5 It was not clear whether higher mobility or larger depletion width would lead to better PIN detectors.

Four samples grown at V-III $=86$ and 172 were then compared by looking at roomtemperature photoluminescence (PL) data. The PL intensities were all quite similar, but slightly higher in both comparisons for the two samples with V-III $=172$. It was decided that the wafers to be processed into neutron detectors would use both recipes, being compared by device testing. A typical photoluminescence measurement is shown in Figure 6. 
MO3-3229-2

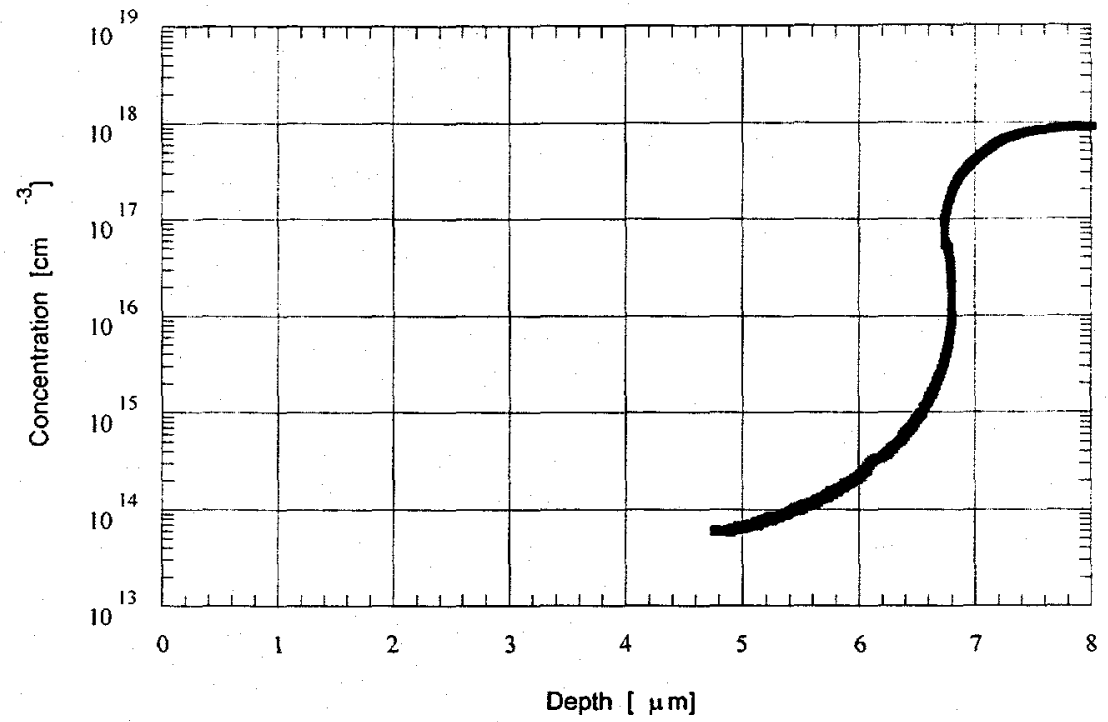

Figure 4 Polaron ${ }^{\mathrm{TM}}$ profile of sample number M3-3229, undoped GaAs, $\approx 6 \mu \mathrm{m}$ thick, grown at $675^{\circ} \mathrm{C}, V-I I I=86$. Undoped carrier concentration is measured to be $\mathrm{n}=6 \times 10^{13} \mathrm{~cm}^{-3}$, with a zero-bias depletion depth of $4.7 \mu \mathrm{m}$.

MO3-3230-2

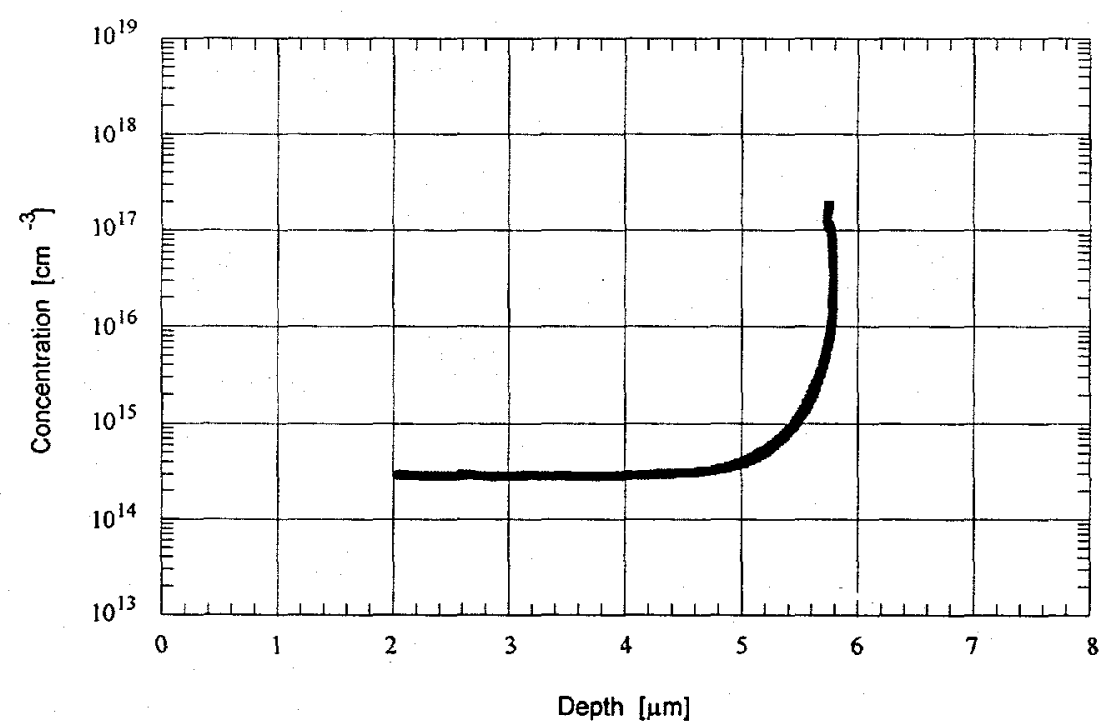

Figure 5 Polaron ${ }^{T M}$ profile of sample number M3-3230, undoped GaAs, $\approx 6 \mu \mathrm{m}$ thick, grown at $675^{\circ} \mathrm{C}, \mathrm{V}-1 \mathrm{II}=172$. Undoped carrier concentration is measured to be $\mathrm{n}=3 \times 10^{14} \mathrm{~cm}^{-3}$, with a zero-bias depletion depth of $2 \mu \mathrm{m}$. 


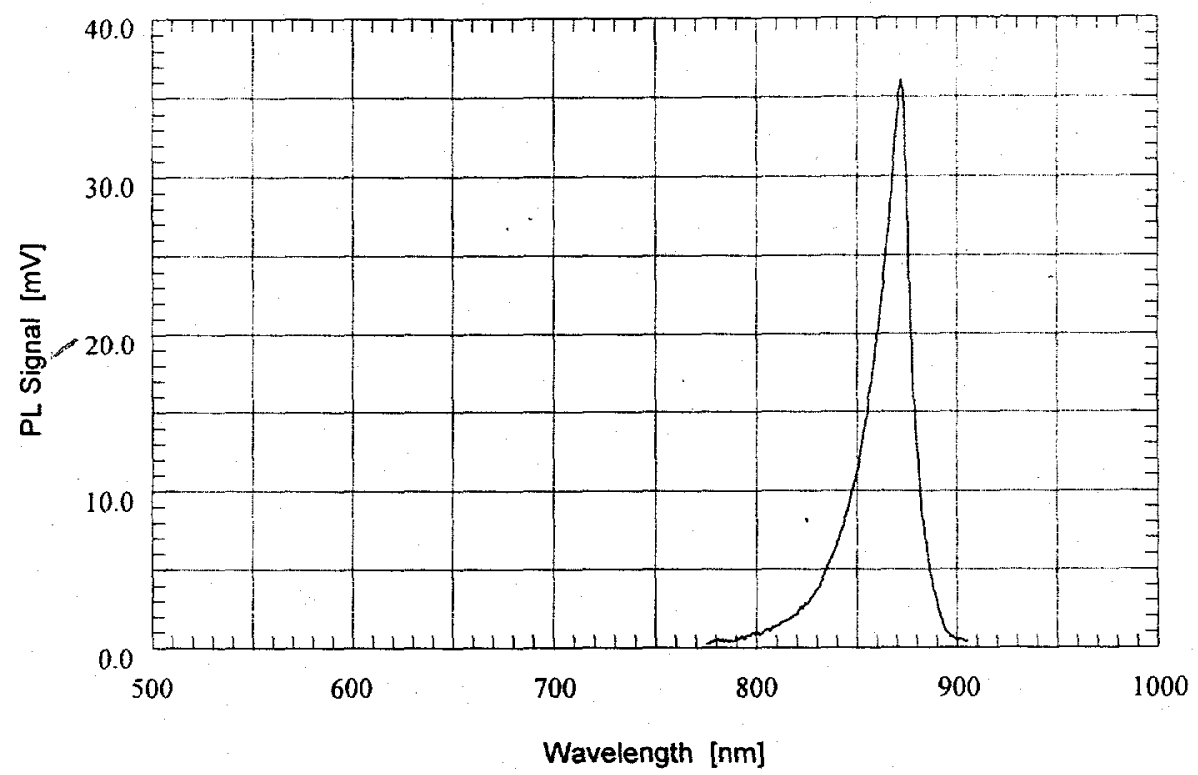

Figure 6 Room-temperature photoluminescence data for sample M3-3229, undoped GaAs, $\approx$ $6 \mu \mathrm{m}$ thick, grown at $675^{\circ} \mathrm{C}, \mathrm{V}-\mathrm{III}=86$.

\subsection{Minority-carrier Lifetime in GaAs}

Another test of material quality is minority-carrier lifetime. This was measured by Dr. Dick Ahrenkiel at National Renewable Energy Laboratory (NREL), using the time-resolved photoluminescence method.

Samples M3-3229 and 3230 were measured for minority-carrier lifetime; 3229 was grown with a V-III ratio of $86,7 \mu \mathrm{m}$ thick, while 3230 was $6 \mu \mathrm{m}$ thick and used a ratio of 172 . We hoped to see a lifetime difference between the two samples which would correlate with measured difference in detector performance. Since the internal QE data (section 3.7) is generally higher for the samples grown with V-III $=86$ than those with V-III $=172$, we would expect the 86-ratio samples to show higher minority-carrier lifetime. The undoped GaAs surface was not passivated by any cap layer; this led to measurement of a very short lifetime, which represents the diffusion-limited lifetime, in which carriers recombine at the unpassivated top surface. Lifetime values measured this way are $20 \mathrm{nsec}$ for 3229 and $17 \mathrm{nsec}$ for 3230 ; these values are several orders of magnitude shorter than typically measured for good undoped GaAs layers.

These samples were then placed back into the MOCVD reactor for addition of a passivating layer, which is $\mathrm{Al}_{\mathrm{x}} \mathrm{Ga}_{1-\mathrm{x}} \mathrm{As}, \mathrm{x} \approx 0.3, \mathrm{n} \approx 5 \times 10^{17} \mathrm{~cm}^{-3}$, about $0.1 \mu \mathrm{m}$ thick. The GaAs surface appeared quite contaminated from handling and storage, but the $\mathrm{Al}_{\mathrm{x}} \mathrm{Ga}_{1-\mathrm{x}} \mathrm{As}$ was added anyway. We would not expect the best interface passivation in this case, but surface recombination velocity should still be lower than for bare GaAs. Actually, the SRV was estimated by researchers at NREL to be quite low, 200 to $1000 \mathrm{~cm} / \mathrm{s}$. 
Results of these new measurements on the passivated samples are that lifetimes now show up as \#3229 = $1.63 \mu$ s and \#3230=0.67 $\mu$ s, values that are reasonable for undoped GaAs. The difference may reflect increased quality of sample \#3229, or may simply be due to the doping differences. According to Polaron data, 3229 was about $6 \times 10^{13} \mathrm{~cm}^{-3}$, while 3230 is five times higher at $3 \times 10^{14} \mathrm{~cm}^{-3}$.

\subsection{P+ Cap Layer}

The next task was to calibrate the $\mathrm{p}+\mathrm{GaAs}$ for the top layer of the PIN structure. This was done using carbon doping, with carbontetrabromide $\left(\mathrm{CBr}_{4}\right)$ as the doping source. We have much experience with this type of layer from our work on heterojunction bipolar transistor (HBT) programs, where the base layer is $\mathrm{p}$ type, $\approx 5 \times 10^{19} \mathrm{~cm}^{-3}$. For HBTs, this layer is grown at $640^{\circ} \mathrm{C}$. To avoid changing the temperature at the undoped-P+ interface, we tried growing this layer at $675^{\circ} \mathrm{C}$. We obtained a doping level of approximately $2 \times 10^{19} \mathrm{~cm}^{-3}$, which should be quite adequate for this structure.

\subsection{Wafers for Processing}

Nine wafers to be processed were then grown. These included the two undoped recipes $(\mathrm{V}-\mathrm{III}=86$ and 172) and three different undoped thicknesses $(1,2$, and $5 \mu \mathrm{m})$. Wafers with an $\mathrm{Al}_{\mathrm{x}} \mathrm{Ga}_{1-\mathrm{x}} \mathrm{As} \mathrm{BSF}$ and a wafer with no $\mathrm{P}+$ cap for Schottky barrier fabrication were produced also.

In order to study the effect of having a back-surface field (BSF) in the structure, we had to develop a layer of $\mathrm{Al}_{\mathrm{x}} \mathrm{Ga}_{1-\mathrm{x}} \mathrm{As}(\mathrm{x} \approx 0.3)$ that is $\mathrm{n}$ type. We decided to try making this layer $\mathrm{n}$ type by adjusting the growth conditions, so we would not introduce a n-type dopant that might cause the undoped GaAs to have a higher background carrier concentration. Since the undoped GaAs layer is $n$ type, the $\mathrm{Al}_{\mathrm{x}} \mathrm{Ga}_{1-\mathrm{x}}$ As must be $\mathrm{n}$ type to avoid having back-to-back diodes, instead of a simple junction.

We first tried growing $\mathrm{Al}_{\mathrm{x}} \mathrm{Ga}_{1-\mathrm{x}} \mathrm{As}$ at $675^{\circ} \mathrm{C}$, with a V-III of 60 or 120 , at a growth rate $\approx$ $16 \AA / \mathrm{sec}$. The surface quality was fine, but neither Hall nor Polaron measurements were able to measure the electrical properties. We raised the growth temperature to $725^{\circ} \mathrm{C}$, at $\mathrm{V}-\mathrm{III}=78$, but the layer could still not be shown to be $\mathrm{n}$ type. We then raised the ratio to 140 , and lowered the growth rate to $\approx 4 \AA / \mathrm{sec}$; this gave an undoped $\mathrm{Al}_{\mathrm{x}} \mathrm{Ga}_{1-\mathrm{x}}$ As layer that the Polaron and Hall data both showed to be $\mathrm{n}$ type, with $\mathrm{n} \approx 5 \times 10^{15} \mathrm{~cm}^{-3}$. These were the conditions used in the device structures.

The next two wafers for processing were then grown. These two have the $\mathrm{Al}_{\mathrm{x}} \mathrm{Ga}_{1-\mathrm{x}} \mathrm{As}$ $\mathrm{BSF}$ layer, the undoped GaAs grown at V-III $=172$, and GaAs thicknesses of 2 and $5 \mu \mathrm{m}$. A schematic of a PIN structure with an $\mathrm{Al}_{x} \mathrm{Ga}_{1-x} \mathrm{As} \mathrm{BSF}$ is shown in Figure 7 The last wafer grown (\# 3278) was to be processed as a Schottky barrier, to be compared with the PIN diodes. This wafer used an undoped GaAs layer, with no P+ cap. An intermediate value of V-II ratio was used here. Table 2 gives descriptions of the nine wafers grown for device processing into detectors. Since facilities and time at University of Michigan were limited, only six wafers were processed; these are numbers $3241,3242,3243,3246,3247$, and 3278 . This group includes the three undoped thicknesses, the two V-III ratios, an AlGaAs BSF, and the SB diode. 


\begin{tabular}{|c|}
\hline $\mathrm{P}+\mathrm{GaAs}, \approx 2 \times 10^{19} \mathrm{~cm}^{-3}, 2000 \AA$ \\
\hline $2 \mu \mathrm{m}$ undoped GaAs $\left(675^{\circ} \mathrm{C}, \mathrm{V}-\mathrm{III}=(172)\right.$ \\
\hline $\mathrm{Al}_{\mathrm{x}} \mathrm{Ga}_{1-\mathrm{x}} \mathrm{As}(\mathrm{x} \approx 0.30)$ undoped $\mathrm{n} \approx 5 \times 10^{15} \mathrm{~cm}^{-3} 2500 \AA$ \\
\hline $2^{\prime \prime}$ diameter GaAs $(100)$ wafer \\
$\mathrm{n} \approx 2 \times 10^{18} \mathrm{~cm}^{-3}$ \\
\end{tabular}

Figure 7

Schematic of wafer number M3-3247, with $\mathrm{Al}_{\mathrm{x}} \mathrm{Ga}_{1-\mathrm{x}} \mathrm{As}$ back-surface field.

Table 2

Wafers grown for device processing. Bold indicates wafers actually coated with boron at University of Michigan.

\begin{tabular}{|c|c|c|c|}
\hline Wafer M3 - & $\begin{array}{c}\text { Undoped GaAs } \\
\text { thickness }(\mu \mathrm{m})\end{array}$ & $\begin{array}{c}\text { Undoped GaAs V-III } \\
\text { ratio }\end{array}$ & Al $_{\times} \mathrm{Ga}_{1-\times}$ As BSF \\
\hline 3241 & 5 & 86 & NO \\
\hline 3242 & 2 & 86 & NO \\
\hline 3243 & 5 & 172 & NO \\
\hline 3244 & 2 & 172 & NO \\
\hline 3245 & 1 & 172 & NO \\
\hline 3246 & 1 & 86 & NO \\
\hline 3247 & 2 & 172 & YES \\
\hline 3248 & 5 & 172 & YES \\
\hline 3278 & 5 & 115 & NO \\
\hline
\end{tabular}

\subsection{Processing and Testing Of Devices}

\subsubsection{Processing at Spire}

The wafers were processed at Spire, with the final step (boron deposition) performed at University of Michigan. The design fabricated is shown in Figure 8, which is somewhat different from that shown in Figure 2. The process at Spire consisted of applying a full-area back metal ohmic contact, made of nickel, gold germanium, and nickel layers $(50 \AA / 3000 \AA / 300 \AA)$, covered by $3000 \AA$ of silver. This scheme has previously been developed at Spire for forming low-resistance contacts on n-type GaAs. On the Schottky-barrier wafer only, the front surface received layers of $50 \AA$ chromium followed by $150 \AA$ gold. All nine wafers were then exposed to the photomask for forming the individual diodes, approximately 90 per two-inch wafer. The diodes were then etched into mesas for isolation. A contact pad on each mesa $(500 \times 500 \mu \mathrm{m})$, and a $100-\mu \mathrm{m}$ thick grid line around the perimeter were applied to complete the Spire fabrication. 
A schematic of the top of a PIN diode is shown in Figure 8; this geometry is simpler than that proposed, shown in Figure 2, to give quick data in Phase I without the possible complications arising from the silicon nitride insulator. The device of Figure 2 will be pursued when complete arrays are studied in Phase II.

\section{Mesa is $3 \mathrm{~mm} \times 3 \mathrm{~mm}$}

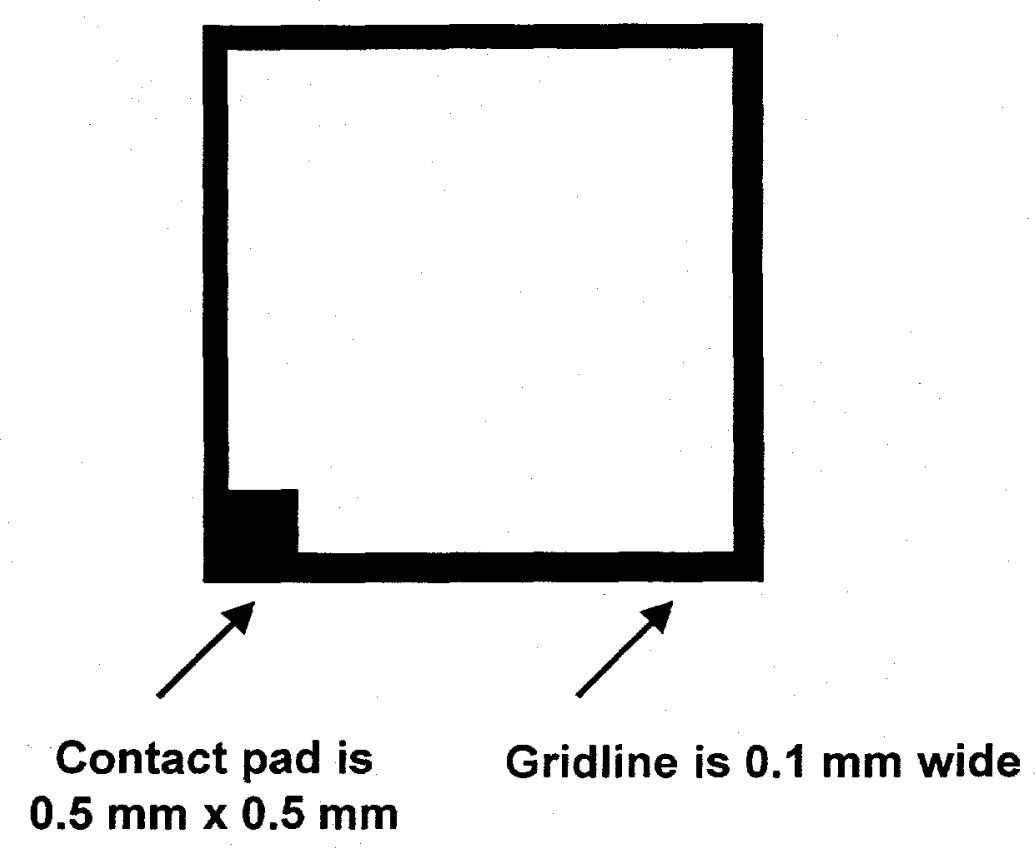

Figure 8 Schematic of mesa diode grid pattern.

\subsubsection{Testing at Spire}

After processing at Spire, wafers were tested at Spire before being sent to University of Michigan for boron evaporation. Several diodes were measured from each two-inch wafer processed. Testing at Spire included measurement of dark I-V curves, external quantum efficiency (EQE) and reflectance (R), capacitance, and contact resistance using a transmissionline test pattern. Internal $\mathrm{QE}(\mathrm{IQE})$ is deduced from measuring $\mathrm{EQE}$ and reflectance, then calculating IQE = EQE / (1-R), which ignores absorption in the Schottky barrier metal. The measured data for I-V, external QE, and internal QE are shown in Figures 9 through 11.

The PIN diodes were all significantly better than the Schottky barrier device, which had six orders of magnitude higher dark current than the best diode, and at least three orders of magnitude higher current than any PIN diode. Due to absorption in the metal layer of the Schottky barrier, the IQE has a maximum of only $30 \%$. 


\section{Dark Current vs Voltage}

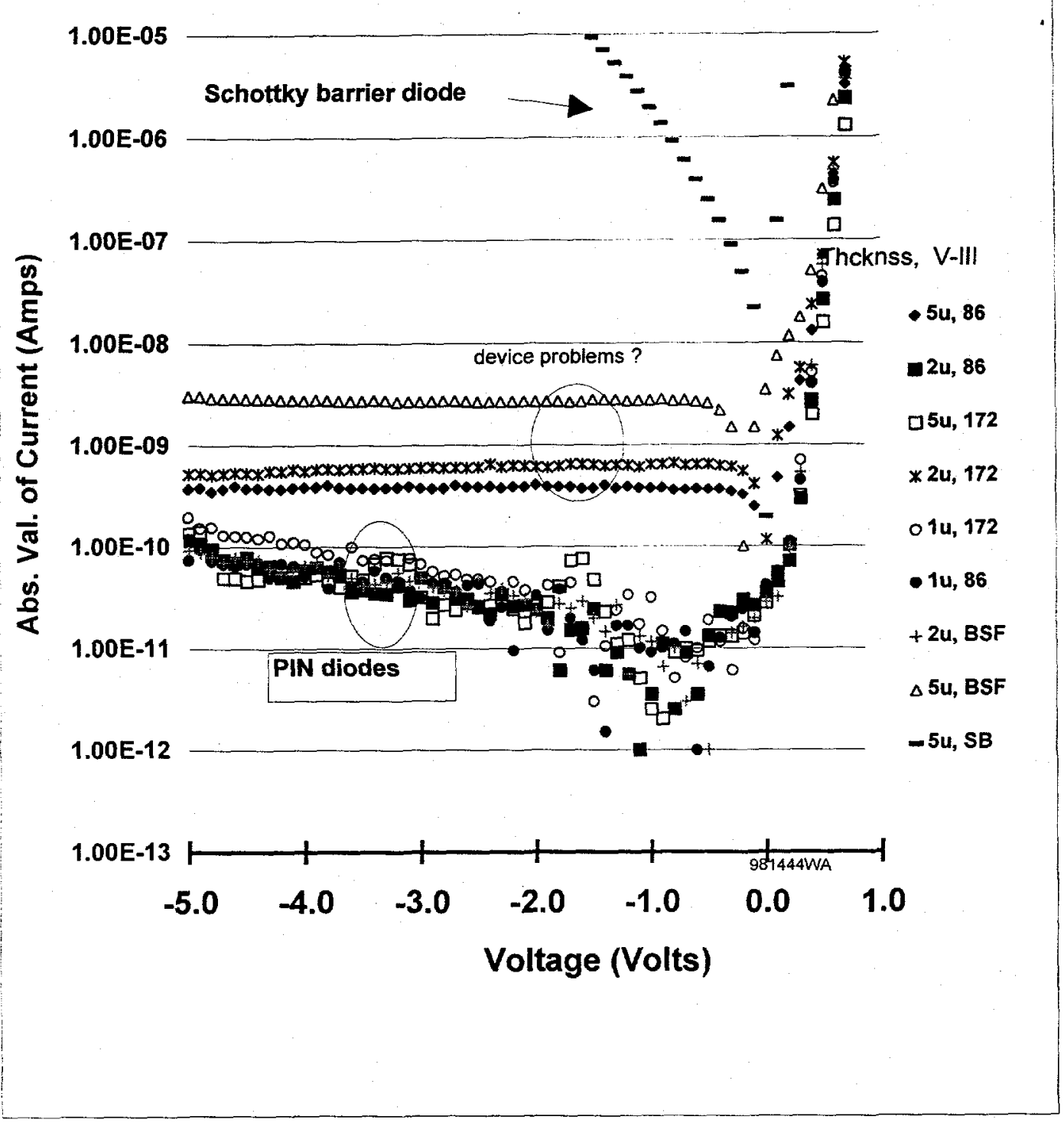

Figure 9 Measured current-voltage data for the nine diodes (eight PINs, and one SB). The $S B$ diode has a dark current that is about six orders of magnitude higher than the best PIN, and at least three orders of magnitude larger than any PIN diode. A logarithmic scale is used, so all values are plotted as positive numbers. 


\section{Internal Quantum Efficiency}

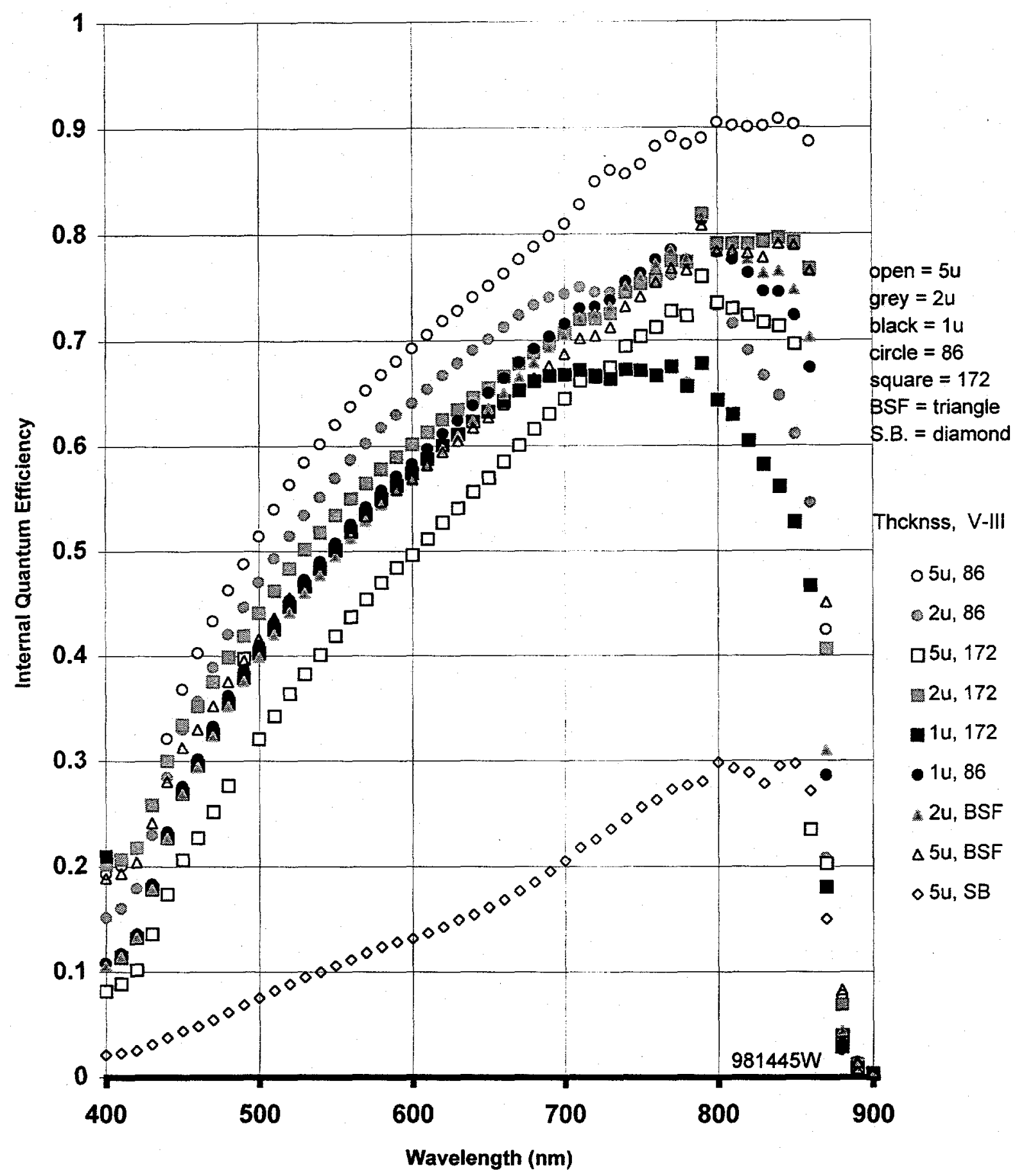

Figure 10 Measured internal quantum efficiency data $(400-900 \mathrm{~nm})$ for the nine diodes of Figure 9. The best diode has over $90 \%$ IQE near the GaAs bandedge. 


\section{EXTERNAL QUANTUM EFFICIENCY}

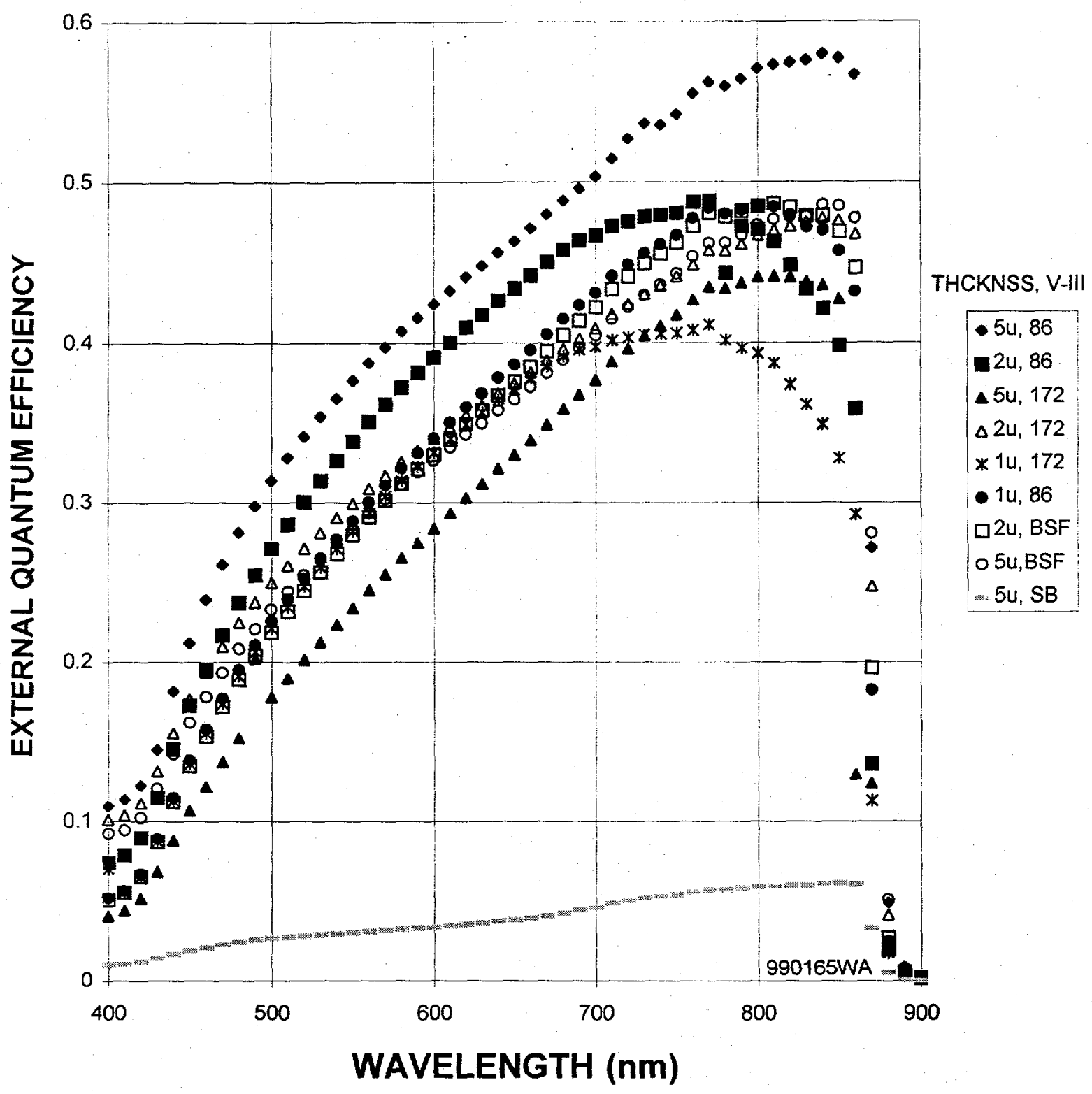

Figure 11 Measured external quantum efficiency data $(400-900 \mathrm{~nm})$ for the nine diodes of Figure 9. 
From the light and dark testing at Spire, it is not clear which epitaxial structure has the best performance. From current-voltage data, the three worst PIN diodes have epitaxial layers that are $2 \mu \mathrm{m}$ with high V-III ratio, $5 \mu \mathrm{m}$ with low V-III ratio, and $5 \mu \mathrm{m}$ with high V-III ratio and the $\mathrm{Al}_{\mathrm{x}} \mathrm{Ga}_{1 \cdot \mathrm{x}}$ As BSF. Yet from IQE data, the device with GaAs which is $5 \mu \mathrm{m}$, low V-III has the best performance. The diodes grown with a V-III of 86 have higher QE at most wavelengths, which may be correlated to the lower carrier concentration and higher lifetime, as measured by time-resolved photoluminescence.

The devices were also tested by contact resistance measurements, looking at resistances of pads spaced $20,40,80,160,320$, and $480 \mu \mathrm{m}$ apart. These data yielded a sheet resistivity value for the P+ cap layers. Assuming that these layers were $0.2 \mu \mathrm{m}$ in thickness (which we had measured on the Polaron profile) the contact resistance data showed the doping level on all devices to be $1.4-1.7 \times 10^{19} \mathrm{~cm}^{-3}$, close to the design goal of $2 \times 10^{19} \mathrm{~cm}^{-3}$.

\subsubsection{Testing of Response to Alpha Particles}

Testing the response to alpha particles is a very good way to test the response of a semiconductor neutron detector. This is due to the fact that incoming thermal neutrons are converted in the layer of boron, giving off an alpha particle and a lithium ion. This step is well understood and documented. The alpha particles (or lithium ions) traveling through the semiconductor create electron-holes pairs, which are collected at the junction. Therefore, measuring the response of the semiconductor diode to alpha particles directly tells us much about its performance as a neutron detector.

Before application of the boron-10 film, several device wafers were tested at Spire with an alpha-particle source, Americium-241. The wafers tested here were not the same samples sent to University of Michigan, but other pieces from the same growth run and process batch. In this test, the I-V curves were measured with no source present, and with the Americium-241 source material laying on top of the device. All tests were performed in the dark.

The radiation response of selected devices was tested by measuring the current-voltage curve while irradiating the device with a $1 \mathrm{mCi}^{241} \mathrm{Am}$ alpha particle source (5.4-5.5 MeV). The source was placed directly over the device under test so that the active device area was exposed to approximately one-quarter of the particle flux from the source (approximately $10^{7} \mathrm{a} / \mathrm{s}$ ). The 5.5 $\mathrm{MeV}$ particles from 241-Am have a range in GaAs calculated to be $20.2 \mu \mathrm{m}$ while the $1.47 \mathrm{MeV}$ alphas from the neutron-boron interaction have a range of only $4.2 \mu \mathrm{m}$. If the full energy of the alpha particles were absorbed by the detector, the upper limit on the radiation-generated current would be approximately:

$$
I \approx \frac{q N E}{\varepsilon} \approx \frac{\left(10^{-19} C\right)\left(10^{7} s^{-1}\right)\left(5 \times 10^{6} \mathrm{eV}\right)}{4 \mathrm{eV}} \approx 1 \mu \mathrm{A}
$$

where $q$ is the magnitude of the electron charge, $N$ is the number of particles incident on the detector per unit time, $\mathrm{E}$ is the energy of the particles, and $\mathrm{e}$ is the electron-hole pair production energy. Since the devices are not sufficiently thick to absorb all of the energy of the incident particles, for perfect devices we would expect a radiation-generated current on the order of $100 \mathrm{nA}$. 
$\mathrm{I}-\mathrm{V}$ curves with and without the alpha source for the tested devices are shown in Figures 12 and 13. A general summary of results is as follows: For the GaAs PIN devices there is a significant zero-bias, radiation-induced current, and applying a reverse bias does not increase the current significantly. As expected, the thicker devices exhibit a larger radiation-induced current, since they absorb a larger fraction of the particles' energy. The device with an AlGaAs back-surface layer exhibited a zero-bias, radiation-induced current much larger than that of the other $5 \mu \mathrm{m}$-thick device, and this current increased when a reverse bias was applied. The Schottky device had a small zero-bias radiation-induced current, but when operated at a reversebias showed a current nearly comparable to the PIN devices.

Details of the wafers tested are shown in Table 3

Table $3 \quad$ Wafers tested by radiation from Americium-241.

\begin{tabular}{|c|c|c|c|}
\hline $\begin{array}{l}\text { RUN } \\
\text { M3 - }\end{array}$ & $\begin{array}{c}\text { UNDOPED } \\
\text { THICKNESS }(\mu \mathrm{m})\end{array}$ & V-III RATIO & $\begin{array}{c}\text { INCLUDES } \\
\mathrm{Al}_{x} \mathrm{Ga}_{1-x} \mathrm{As} \text { BSF ? }\end{array}$ \\
\hline 3242 & 2 PIN & low & no \\
\hline 3243 & 5 PIN & high & no \\
\hline 3244 & 2 PIN & high & no \\
\hline 3245 & 1 PIN & high & no \\
\hline 3248 & $5 \mathrm{PIN}$ & high & yes \\
\hline 3278 & $5 \mathrm{SB}$ & medium & no \\
\hline
\end{tabular}

As explained in Section 3.2, the low V-III ratio gave undoped GaAs with large zero-bias depletion width, but only fair mobility, while the higher V-III ratio gave smaller depletion, but higher mobility. Room-temperature photoluminescence intensities were slightly higher for the films grown with the high V-III ratio.

Wafer 3278 was processed as the Schottky-barrier device, covered with chrome-gold. For most PIN devices (except for the BSF structure), reverse bias currents (both in the dark and with Am-241) were quite flat. This indicates that an applied bias is not needed for operation of these detectors.

On both 3248 (BSF) and 3278 (SB), the dark currents are higher and not as flat as on the first four. For 3248, the BSF seems to be causing the higher dark current, which may indicate problems at the $\mathrm{Al}_{\mathrm{x}} \mathrm{Ga}_{1-\mathrm{x}} \mathrm{As}-\mathrm{GaAs}$ interface. However, the response to alpha particles is several times higher than on other wafers; in fact, the radiation-generated current level is fairly close to the upper limit estimated above. A BSE works well in solar cells, reflecting carriers toward the junction, and is now used in almost all III-V cells. Its use here seems promising, and will be explored further in Phase II. For 3278, the Schottky barrier zero-bias response to alpha particles is somewhat lower than the $5 \mu \mathrm{m}$ PIN device, but it increases with reverse bias to become comparable at a few volts. However, the dark current is 18-90 times higher than the other GaAs PIN devices. The lower value for radiation-induced zero-bias current may represent the effect of the Schottky metal. The loss of energy in the Schottky metal would be even more serious for the lower-energy alpha particles emitted from the boron layer than those used for testing here. 
DIODE RESPONSE TO ALPHA SOURCE

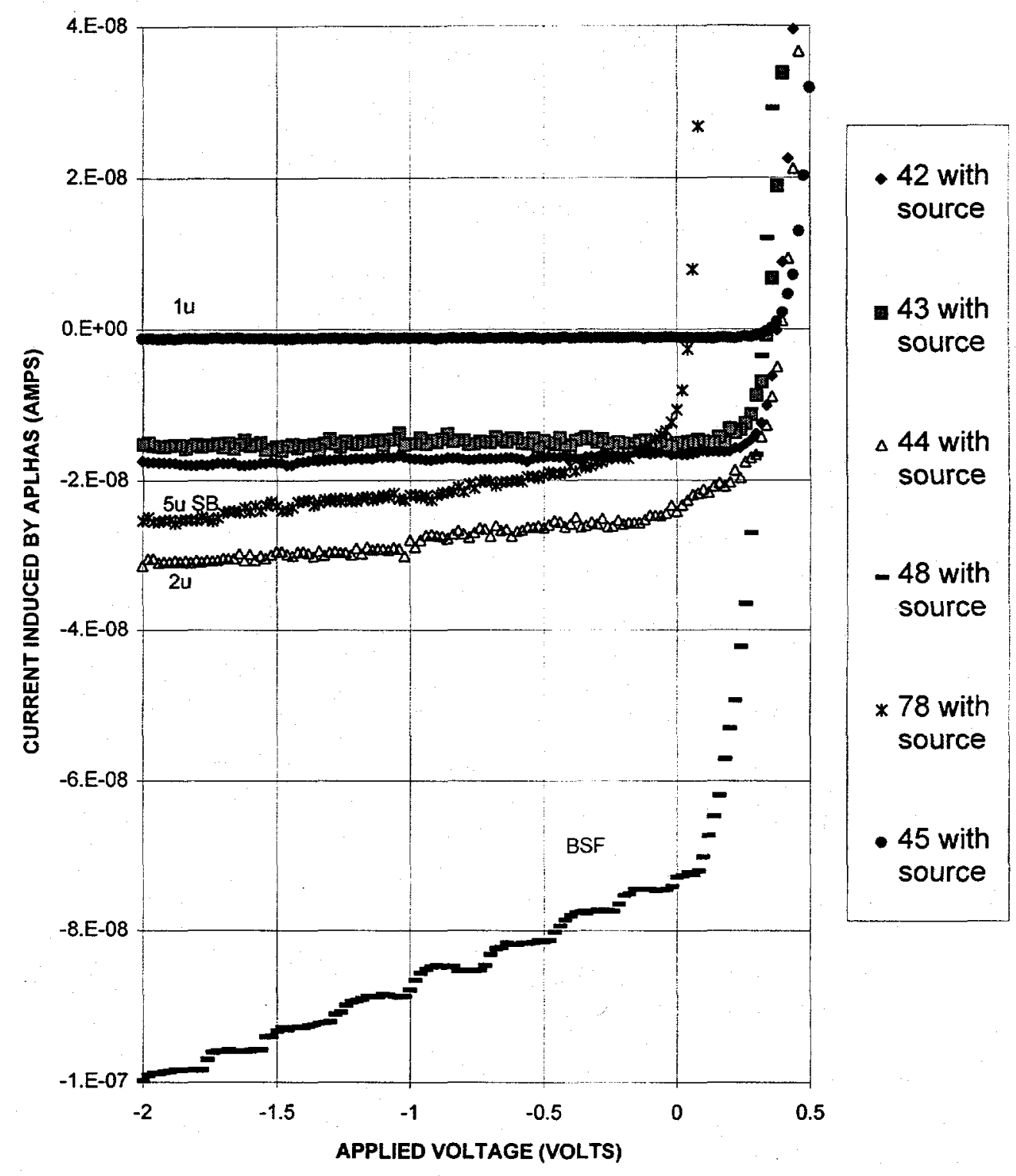

Figure 12 Measured response of the six structure to alpha particles from the 241-Am source. 


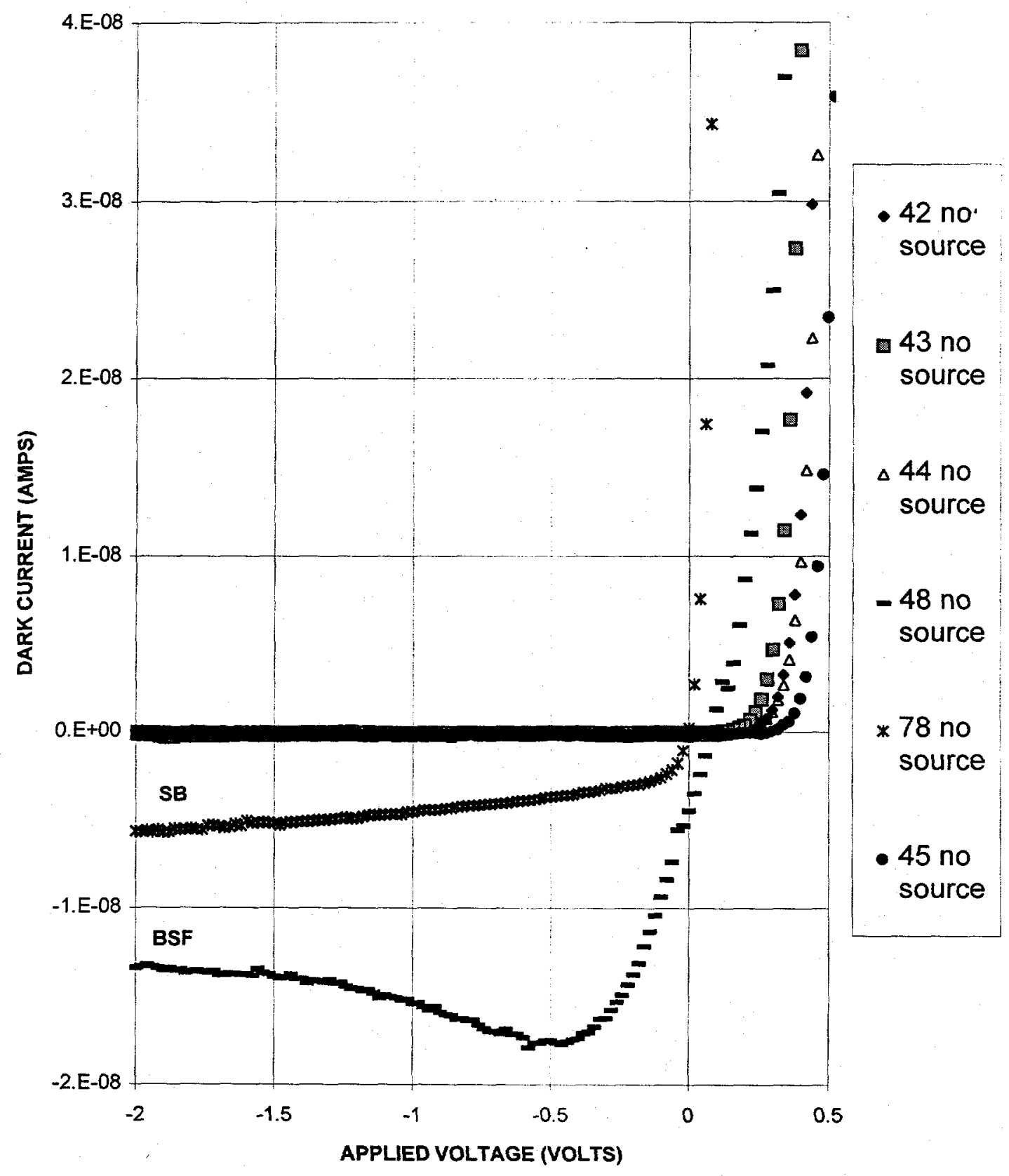

Figure 13 Measured dark-current data for the six test diodes of Figure 12. 
The measured data for these six wafers are shown in Table 4, with actual curves in Figures 12 and 13. At least two devices were measured on each wafer. The general results are:

- thicker devices have higher radiation-generated current

- higher V-III ratio seems to lead to higher sensitivities

- devices on the same wafer are very similar

- devices with AlGaAs BSF produce substantially higher current

- $5 \mu \mathrm{m}$ Schottky devices do not produce as much alpha-induced current as the best $2 \mu \mathrm{m}$ PIN devices

- Device \#3243 shows unexplained results; these may be due to ohmic-contact problems. On this wafer, some devices produce very little current, while others produce higher current. Some devices seemed to degrade immediately upon exposure to the alpha source, so that even after the source was removed they had very large reverse bias currents.

Table 4 Measured dark currents and response to alpha particles.

\begin{tabular}{|c|c|c|c|}
\hline RUN & STRUCTURE & $\begin{array}{c}\text { DARK CURRENT AT - } \\
\text { IV (nA) }\end{array}$ & $\begin{array}{c}\text { ALPHA CURRENT (nA) } \\
\text { AT - } 1 \text { V BIAS }\end{array}$ \\
\hline 3242 & $2 \mu \mathrm{m}$ & 0.05 & 17 \\
\hline 3243 & $5 \mu \mathrm{m}$ & 0.08 & 15 \\
\hline 3244 & $2 \mu \mathrm{m}$ & 0.25 & 28 \\
\hline 3245 & $1 \mu \mathrm{m}$ & 0.1 & 1.2 \\
\hline 3248 & $5 \mu \mathrm{m}, \mathrm{BSF}$ & 15 & 88 \\
\hline 3278 & $5 \mu \mathrm{m}, \mathrm{SB}$ & 4.5 & 22 \\
\hline
\end{tabular}

The dark currents in Table 4 are shown for regions where the current has generally leveled off. The notations in the "structure" column refer to the undoped thickness, with BSF and SB referring to back-surface field and Schottky barrier, respectively.

The dark-current behavior of \#3248 ( $5 \mu \mathrm{m}, \mathrm{BSF})$ is unexplained, possibly resulting from exposure to alpha particles. This device also showed high dark current when tested the first time (during the visible-photon) I-V testing, but it did not show the strange negative-resistance shape displayed in Figure 13. The response to radiation-generated current (in Figure 12) is also unexplained, having a regular step pattern in the I-V curve, with a step approximately every 0.25 V. Also, in photovoltaic diodes, the use of a BSF does not increase photocurrent by more than a factor of two, as shown here. However, as increased efficiency with the BSF is clearly shown here, on all devices tested on this wafer, this structure should be more fully explored.

The effects of the $\mathrm{Al}_{\mathrm{x}} \mathrm{Ga}_{1-\mathrm{x}} \mathrm{As} \mathrm{BSF}$ on alpha-particle generated current are puzzling at this time. Possibly the aluminum in the $\mathrm{Al}_{\mathrm{x}} \mathrm{Ga}_{1-\mathrm{x}} \mathrm{As}$ acts as a getterer during MOCVD growth, serving to purify the GaAs layer somewhat. This would increase the depletion width, enhancing the collection efficiency. The $\mathrm{Al}_{\mathrm{x}} \mathrm{Ga}_{1-\mathrm{x}} \mathrm{As}-\mathrm{GaAs}$ interface may then have a collection of impurity 
states. The interaction of these interface states with alpha particles may possibly lead to the "quantized" steps apparent in Figure 12.

\subsubsection{Processing at University of Michigan - Deposition of Boron-10}

Wafers of GaAs epitaxial detection devices fabricated at Spire were cleaned in a series of solvents and prepared for boron deposition. Each wafer was attached to a clean glass slide, device side up, with $5214 \mathrm{E}$ photoresist and baked at $100^{\circ} \mathrm{C}$ for 15 minutes. Afterwards, shadow masks with $1.5 \mathrm{~mm}$ diameter openings pitched at $3.5 \mathrm{~mm}$ each were attached over the GaAs wafers. This allowed for a $1.5 \mathrm{~mm}$ opening to be centered over each $\mathrm{GaAs}$ detection device.

The devices were placed in an electron beam evaporator, in which the evaporator chamber was pumped down to $2.5 \times 10^{-6}$ torr. The neutron reactive coating was applied to the detector through the shadow mask, those being a $300 \AA$ layer of Ti followed by a $6500 \AA$ layer of $96 \%$ enriched ${ }^{10} \mathrm{~B}$. Boron radiates much heat when evaporated, and thermal heating of the wafers causes film separation unless precautions are taken to prevent the effect. Additionally, the heating can cause photoresist mask reflow, hence the reason for choosing a metal shadow mask rather than patterning the devices with conventional photolithography techniques. The $\mathrm{Ti}$ layer acts to promote adhesion of the ${ }^{10} \mathrm{~B}$ to the GaAs device surface.

After the evaporation, the devices were removed from the chamber and cleaned in a series of solvents. The neutron reactive film layer thickness was measured with a profilometer, indicating an average thickness of approximately $6848 \AA$ (see Figure 14). The wafers were scribed and cleaved into the individual detectors. The backside contact of each device was mounted with Epotek H-20 silver epoxy to T0-8 headers. The devices were then wire bonded to the header pins. Metal caps were soldered over the headers to eliminate electromagnetic energy interference with the detector signals.

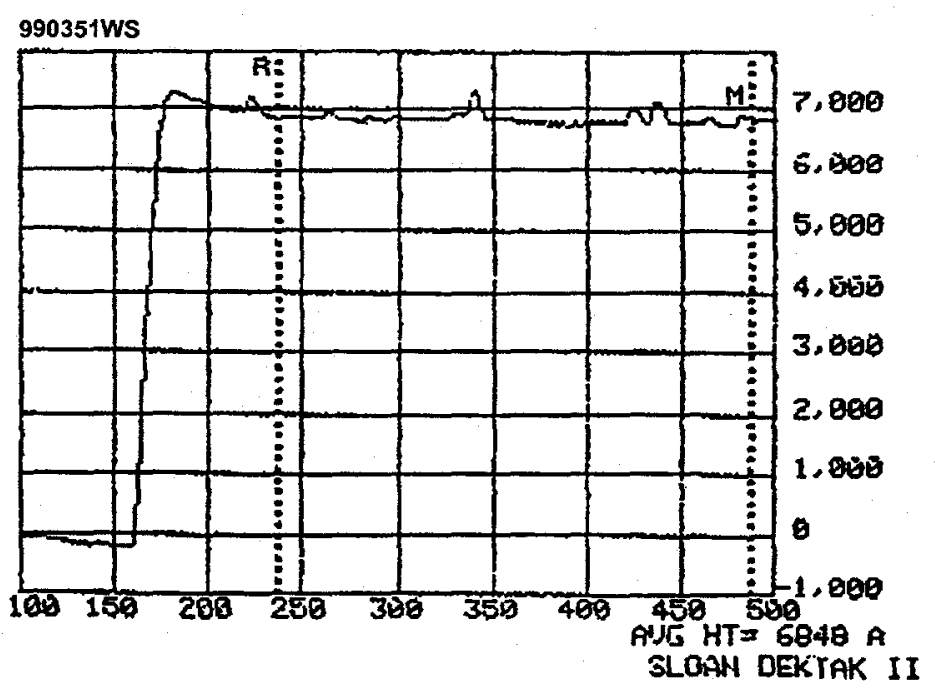

Figure 14 Profilometer measurement of the combined $\mathrm{Ti} /{ }^{10} \mathrm{~B}$ deposited film. 


\subsubsection{Radiation Testing at University of Michigan}

\subsubsection{Basic Theory and Efficiency Curves}

Neutron detectors require an identification method that allows for the unique recognition of a neutron interaction. Since neutrons hold no electronic charge, methods used to recognize neutron interactions within a device generally rely on second order effects. A popular neutron interaction used for a variety of thermal neutron detectors is the ${ }^{10} \mathrm{~B}(\mathrm{n}, \alpha)^{7} \mathrm{Li}$ reaction which leads to the following reaction products. ${ }^{4}$

$$
{ }^{10} \mathrm{~B}+\mathrm{n} \rightarrow\left\{\begin{array}{cc}
{ }^{7} \mathrm{Li}(\text { at } 1.015 \mathrm{MeV})+\alpha(\text { at } 1.777 \mathrm{MeV}), & \text { Reaction Q- Value } \\
{ }^{7} \mathrm{Li}^{*}(\text { at } 0.840 \mathrm{MeV})+\alpha(\text { at } 1.470 \mathrm{MeV}), & 2.310 \mathrm{MeV}(\text { to ground state })
\end{array}\right.
$$

where thermal neutrons $(0.0259 \mathrm{eV})$ absorbed by ${ }^{10} \mathrm{~B}$ produce energetic particles that are released in opposite directions $\left(180^{\circ}\right.$ apart). After absorption, $94 \%$ of the reactions leave the ${ }^{7} \mathrm{Li}$ ion in its first excited state, in which it rapidly de-excites to the ground state $\left(\sim 10^{-13}\right.$ seconds $)$ by releasing a $480 \mathrm{keV}$ gamma ray. The remaining $6 \%$ of the reactions result in the ${ }^{7} \mathrm{Li}$ ion going directly to its ground state. The microscopic thermal neutron $(0.0259 \mathrm{eV})$ absorption cross section is 3840 barns. Additionally, the microscopic thermal neutron absorption cross section decreases with increasing neutron energy, with the cross section dependence being proportional to the inverse of the neutron velocity $(1 / v)$ over much of the energy range. ${ }^{5}$ The neutron detector presently discussed consists of a GaAs solid state detector coated with a thin film layer of enriched ${ }^{10} \mathrm{~B}$ material.

Thin film neutron detectors consist of semiconductor diodes, preferably with very thin contact layers, on which have been deposited a layer (or layers) of neutron reactive material. Shown in Figure 15, neutrons absorbed in the neutron reactive film release charged particle reaction products in opposite directions, of which only one may enter the semiconductor diode detector. Charged particles entering the detector lose their energy through Coulombic scattering, thereby creating a high-density plasma cloud of columnar ionization in the form of electron-hole pairs. The semiconductor diode detector is voltage biased to separate the electron-hole pairs and move the charges to their respective contacts. The mobile charges induce an image charge on the contacts as they move through the device, and the induced charge is integrated and measured by an external preamplifier and accompanying electronics.

It is important to note the charged particles have discreet ranges within a material, and they lose energy as a function of the "stopping power" of the material through which they pass. ${ }^{6}$ Charged particle energy loss is not linear with distance, and the energy loss for non-relativistic high-energy charged particles can generally be described by the stopping power relation.?

$$
S=-\frac{1}{N} \frac{d E}{d x}=\frac{4 \pi z^{2} q^{4}}{m_{o} v^{2}} Z \ln \left(\frac{2 m_{o} v^{2}}{J}\right)
$$

where $z q$ and $v$ are the charge and the velocity of the charged particle, $N$ is the atom density, $m_{\mathrm{o}}$ is the rest mass of an electron, $Z$ is the material atomic density, and $J$ is an experimentally determined quantity describing the average excitation potential of a representative atom in the 
material. Although the average range is considered discreet, the actual range fluctuates from particle to particle due to deviations in the number of Coulombic scatters per unit distance and deviations in energy loss in per collision. The fluctuation may encompass over $5 \%$ of the total range, and the deviation is referred to as the "straggle" in the particle range. In the unique case of protons, alpha particles, and other relatively low mass heavy ions, the energy loss as a function of distance can be described by the Bragg ionization curve, in which ${ }^{6}$

$$
I(r)=\int_{0}^{\infty} \frac{i(x-r)}{\beta \sqrt{\pi}} e^{-\left[(x-R) / \beta^{2}\right]} d x,
$$

where $x$ is the range of the individual particle, $r$ is the distance that the particle has traveled in the material, $i(x-r)$ is the specific ionization along the path of the ionizing particle at point $(x-r)$ from the end of its path, and $\beta$ is the straggling parameter. An interesting characteristic of the Bragg ionization curve is the increase in columnar ionization per unit volume as the ion energy decreases. Hence, the highest density of electron-hole pairs are excited near the end of the particle range. The effective range (denoted $L$ ) is the distance through which a particle may travel within the neutron reactive film before its energy decreases below the set minimum detectable threshold, or rather, before its energy decreases below the electronic lower level discriminator $(L L D)$ setting. The term does not take into account additional energy losses from contact "dead regions." The neutron reaction products released do not have equal masses, and therefore do not have equal energies or effective ranges. The short range reaction product effective range is denoted $L_{S R}$ and the long range reaction product effective range is denoted $L_{L R}$.

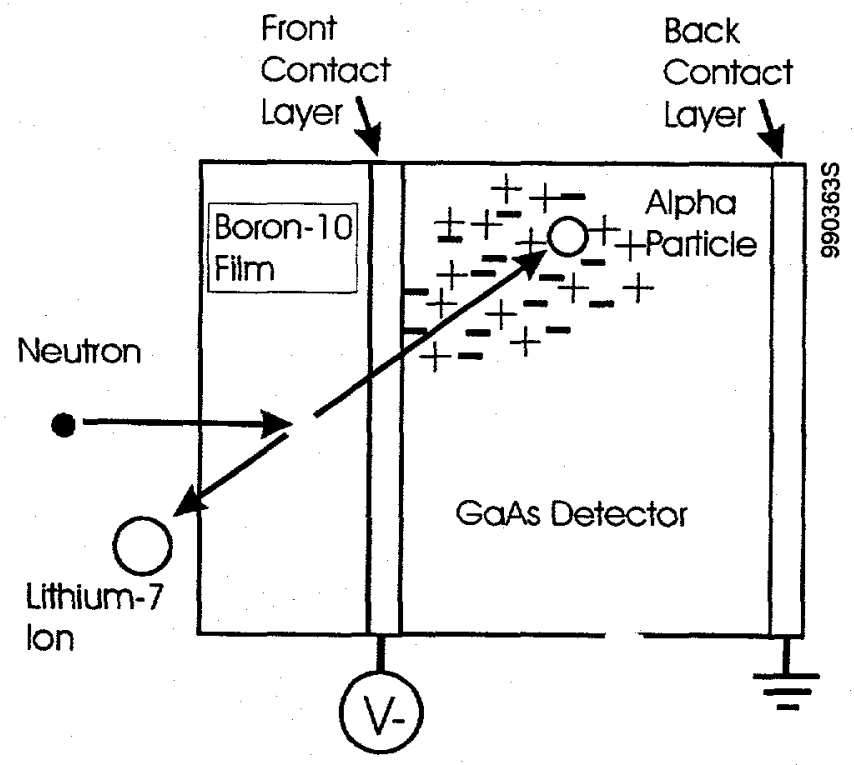

Figure 15 Basic scheme of a boron coated semiconductor neutron detector. Neutrons interact in the ${ }^{10} \mathrm{~B}$ film, which produces a ${ }^{7} \mathrm{Li}$ ion and an alpha particle. Charged particles entering the semiconductor detector excite electron-hole pairs, which give rise to a measurable electronic pulse. 
Neutrons may interact anywhere within the reactive film. From Figure 15, it becomes apparent that the reaction products will also lose energy as they move through the neutron reactive film, referred to as energy self-absorption. Reaction product self-absorption reduces the energy transferred to the semiconductor detector, and ultimately limits the maximum film thickness that can be deposited over the semiconductor device. The voltage signal measured is directly proportional to the number of electron-hole pairs excited within the semiconductor. Reaction products that deposit most or all of their energy in the detector will produce much larger voltage signals than those reaction products that lose most of their energy before reaching the detector. Neutron transmission through the film as a function of distance $x$ can be described by

$$
I(x)=I_{0} e^{-x \sigma_{F} N_{F}}=I_{0} e^{-x \Sigma_{r}},
$$

where $I_{0}$ is the initial neutron flux, $N_{F}$ is the atom density of the neutron reactive isotope in the film, $\sigma_{F}$ is the microscopic thermal neutron absorption cross section of the film, and $\Sigma_{F}$ is the film macroscopic thermal neutron absorption cross section. It becomes obvious that the fraction of neutrons absorbed in the film through distance $x$ is

$$
1-\frac{I(x)}{I_{0}}=1-e^{-x \sigma_{g} N_{f}}=1-e^{-x \Sigma_{f}}
$$

The neutron absorption probability per unit distance is described by

$$
P(x) d x=\Sigma_{F} e^{-x \Sigma_{F}} d x .
$$

The angular contribution to self-attenuation must also be addressed. Once a neutron is absorbed and the reaction products are emitted, the probability that a reaction product particle will enter the detector is determined by the solid angle that the particle effective range allows. From Figure 16, a neutron interaction taking place at distance $x$ from the detector has a probability of entering the detector as described by the fractional solid angle that subtends the detector,

$$
P_{p}(x)=\frac{\Omega(x)}{4 \pi}=\frac{2 \pi}{4 \pi}\left(1-\frac{x}{L}\right)=0.5\left(1-\frac{x}{L}\right), \quad x \leq L
$$

where the subscript $p$ relates to the reaction product particle of interest. Since the reactions of interest in the present work release two different charged particle reaction products per event, the total probability of detecting a reaction necessitates adding the detection probabilities of both particles. It is completely possible that one reaction product may be able to reach the detector while the other reaction product can not. Figure 17 demonstrates the effect of detection efficiency as a function of neutron interaction depth. Interactions occurring near the detector contact result in either particle entering the detector with high probability. As the neutron interaction distance increases, the solid angle of the short range particle decreases more rapidly than that of the long range particle, resulting in an overall decrease in detection sensitivity. At a further distance, the long range particle can no longer reach the detector, hence neutron interactions occurring at greater distances than $L_{L R}$ will go undetected. Ultimately, it serves no purpose to increase the 
neutron reactive thin film beyond $L_{L R}$, and as will be shown, actually works to decrease the overall neutron detection efficiency.

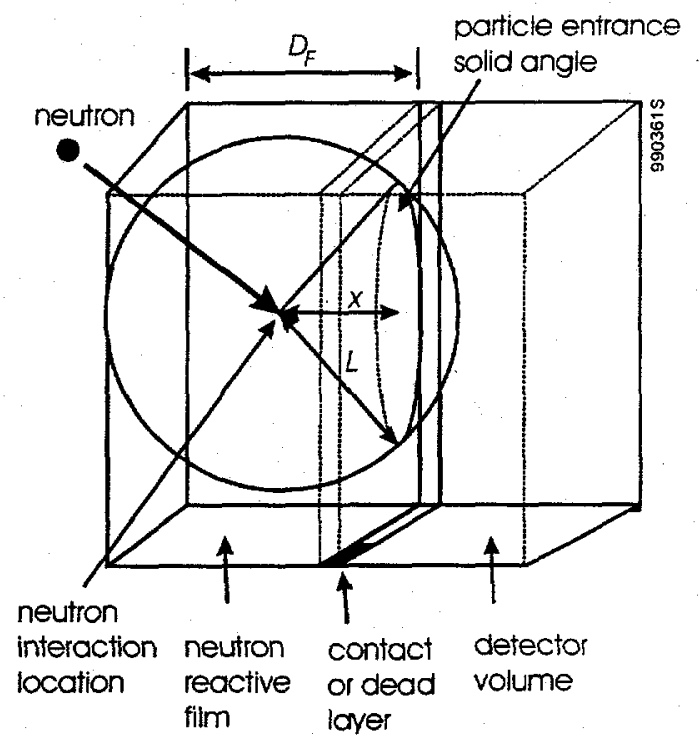

Figure 16 Reaction products given off from a thermal neutron interaction in the ${ }^{10} \mathrm{~B}$ film are emitted isotropically. The solid angle describing the effective particle range that subtends the detector contact interface decreases as the neutron interaction location increases in distance from the contact. Consequently, the probability of a charged particle entering the detector decreases as the solid angle decreases.

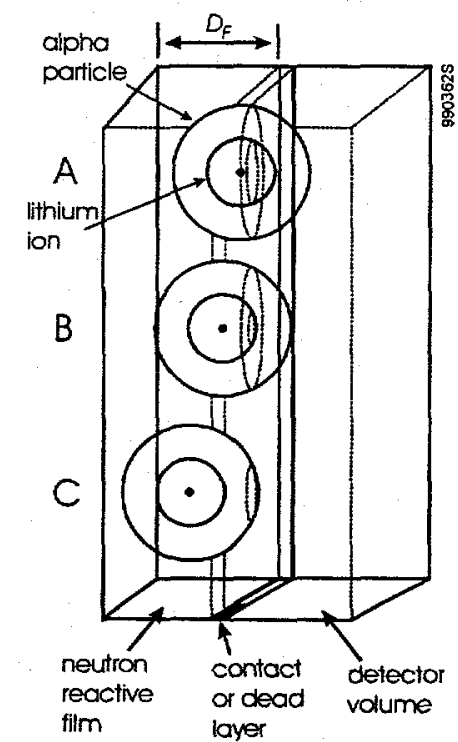

Figure 17 The reaction products have different energies and masses, resulting in different ranges within the neutron reactive film. Interactions near the detector contact interface $(A)$ have a high probability that either the Li ion or the alpha particle will enter the detector. The probability that the $\mathrm{Li}$ ion will enter the detector decreases (B) as the interaction location occurs further from the contact. At interaction locations $(C)$ at and beyond the effective range of the alpha particle, the solid angle diminishes to zero, in which neither particle will enter the detector. 


\subsubsection{Considerations Regarding ${ }^{10} \mathrm{~B}$ Coatings}

As mentioned previously, the primary ${ }^{10} \mathrm{~B}(\mathrm{n}, \alpha)^{7} \mathrm{Li}$ reaction $(94 \%)$ results in the emission of a $1.47 \mathrm{MeV}$ alpha particle and a $840 \mathrm{keV}{ }^{7} \mathrm{Li}$ ion in its first excited state, and the ground state emission results in the emission of a $1.777 \mathrm{MeV}$ alpha particle and a $1.015 \mathrm{MeV}{ }^{7} \mathrm{Li}$ ion. Comparison Bragg ionization curves for both particles within a pure ${ }^{10} \mathrm{~B}$ film are shown in Figure $18 .^{8}$ Clearly shown are the range differences for either ion, in which the average range for a $840 \mathrm{keV}^{7} \mathrm{Li}$ ion in boron is 1.6 microns and the average range for a $1.47 \mathrm{MeV}$ alpha particle is 3.6 microns.

The energy absorbed in the detector is simply the total energy minus the energy lost in the boron film and the detector contact during transit. Assuming that energy loss in the detector contact is negligible, Figure 19 shows the energy retained by either charged particle as a function of transit length through the boron film. At any reaction location within the ${ }^{10} \mathrm{~B}$ film, maximum detector entrance energy will be retained by either particle should it enter the detector in an orthogonal trajectory. Hence, if the interaction occurs in the ${ }^{10} \mathrm{~B}$ film at a distance of 0.5 microns away from the detector, the maximum energy retained by the particle will be $430 \mathrm{keV}$, and the maximum energy retained by the alpha particle will be $1150 \mathrm{keV}$. For the same interaction distance from the detector, the energy retained by the particle when it reaches the detector decreases as the angle increases from orthogonal $\left(0^{\circ}\right)$.

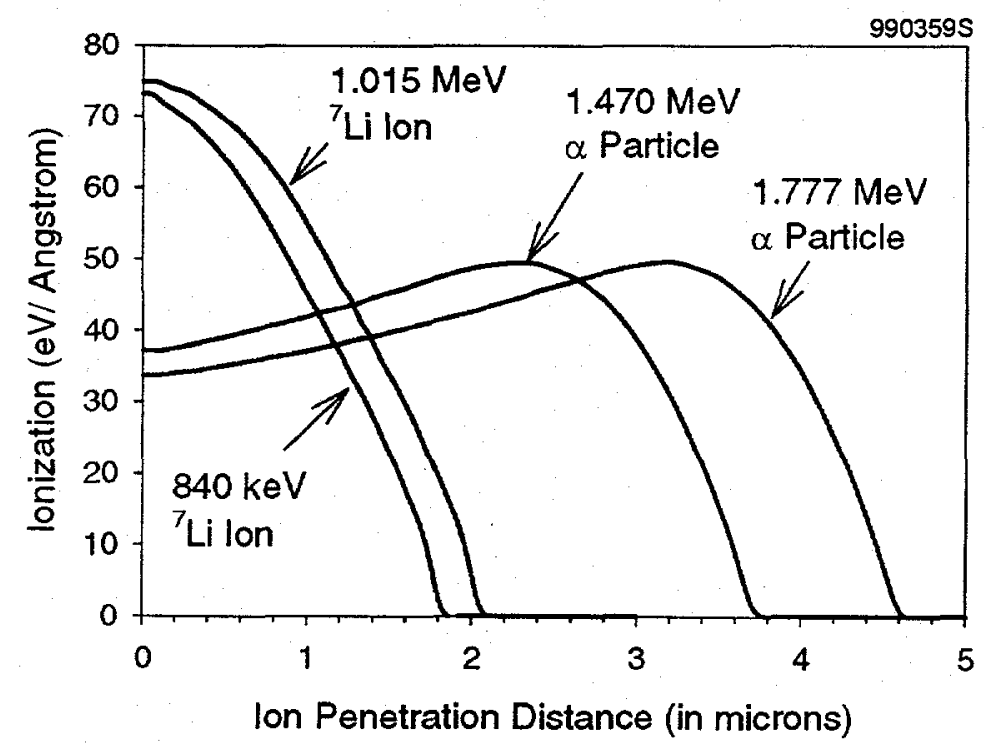

Figure 18 The Bragg ionization distributions in pure ${ }^{10} \mathrm{~B}$ for charged particles emitted from ine ${ }^{10} \mathrm{~B}(\mathrm{n}, \alpha)^{7} \mathrm{Li}$ reaction.

Given a predetermined minimum detection threshold (or $L L D$ setting), the effective range $(L)$ for either particle can be determined. For instance, from Figure 19, an $L L D$ setting of 300 $\mathrm{keV}$ gives $L_{L i}$ as 0.810 microns and $L_{\alpha}$ as 2.648 microns. The microscopic thermal neutron absorption cross section $(\sigma)$ for ${ }^{10} \mathrm{~B}$ is 3840 barns and the atomic density is $1.3 \times 10^{23}$ atoms $/ \mathrm{cm}^{3}$. The resulting macroscopic absorption cross section $(\Sigma)$ is $500 / \mathrm{cm}$. At $300 \mathrm{keV}$, the $\Sigma L$ product for $840 \mathrm{keV}{ }^{7} \mathrm{Li}$ ions is 0.0405 and the $\Sigma L$ product for $1.47 \mathrm{MeV}$ alpha particles is 0.1324 . 


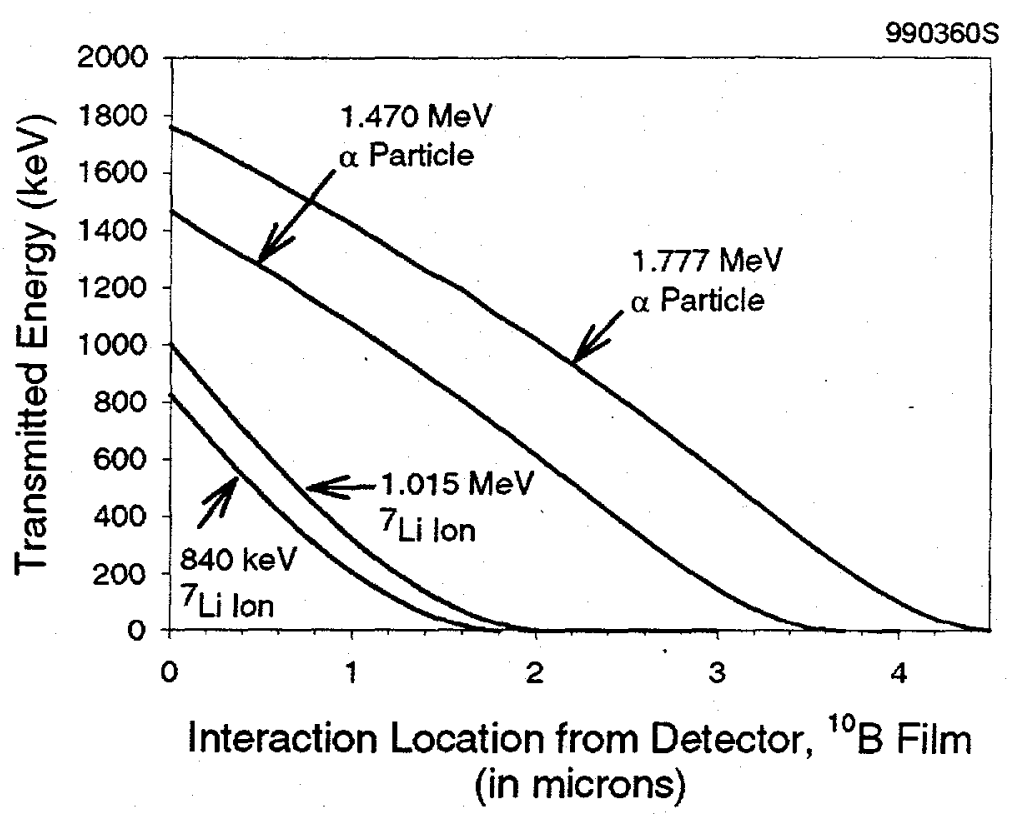

Figure 19 Energy retained by charged particles emitted from the ${ }^{10} \mathrm{~B}(n, \alpha)^{7} \mathrm{Li}$ reaction that enter the GaAs detector orthogonally as a function of interaction location distance from the detector contact interface. Negligible charged particle energy loss in the contact was assumed for the calculation.

The coordinate system shown in Figure 20 is adapted for the following analysis. It is assumed that the contact thickness $\left(D_{l}\right)$ is negligible. Consider the case of a thermal neutron beam orthogonally striking the detector from the front (as shown). Equation 1 becomes

$$
I(x)=I_{0} e^{-\Sigma_{F}\left(D_{F}-x\right)},
$$

where $D_{F}$ is the neutron reactive film thickness and $I_{o}$ is the initial neutron beam intensity before entering the reactive film. Additionally, equation 5 becomes

$$
P(x) d x=\Sigma_{F} e^{-\Sigma_{F}\left(D_{F}-x\right)} d x .
$$

The sensitivity contribution for a reaction product particle can be found by integrating over the product of the interaction probability (equation 8 ) and the fractional solid angle through film thickness $D_{F}$, where 


$$
\begin{aligned}
S_{p}\left(D_{F}\right) & =\frac{F_{p}}{4 \pi I_{0}} \int_{0}^{D_{F}} I_{0} 2 \pi \Sigma_{F} e^{-\Sigma_{r}\left(D_{r}-x\right)}\left(1-\frac{x}{L}\right) d x \\
& =0.5 F_{p}\left\{\left(1+\frac{1}{\Sigma_{F} L}\right)\left(1-e^{-\Sigma_{p} D_{F}}\right)-\frac{D_{F}}{L}\right\},
\end{aligned}
$$

for $D_{F} \leq L$, and

$$
\begin{aligned}
S_{p}\left(D_{F}\right) & =\frac{F_{p} e^{-\Sigma_{F}\left(D_{F}-L\right)}}{4 \pi I_{0}} \int_{0}^{L} I_{0} 2 \pi \Sigma_{F} e^{-\Sigma_{F}\left(D_{r}-x\right)}\left(1-\frac{x}{L}\right) d x \\
& =0.5 F_{p} e^{-\Sigma_{F}\left(D_{F}-L\right)}\left\{\left(1+\frac{1}{\Sigma_{F} L}\right)\left(1-e^{-\Sigma_{F} L}\right)-1\right\},
\end{aligned}
$$

for $D_{F}>L$, where $F_{p}$ refers to the branching ratio of the reaction product emission. The total sensitivity can be found by adding all of the reaction product sensitivities, hence

$$
\left.S\left(D_{F}\right)\right|_{\text {Total }}=\sum_{p=1}^{N} S_{p}\left(D_{F}\right)
$$

where $N$ is the number of different reaction product emissions. In the case of ${ }^{10} \mathrm{~B}$ based films $N$ equals 4 . Notice from equation $9 B$ that the value of $S_{p}$ reduces as $D_{F}$ becomes larger than the value of $L$. As a result, there will be an optimum neutron reactive film thickness for front irradiated detectors. Since the minimum particle detection threshold determines the effective range $(L)$, the optimum film thickness is also a function of the $L L D$ setting.

Overall, the front coated device operates as a simple neutron counter, and requires only sufficient confidence to discriminate between background gamma rays and true neutron events. Hence, the energy discriminator should be set high enough to reduce the probability of mistaking a gamma ray event for a neutron event. Figure 21 shows the expected thermal neutron detection efficiency for ${ }^{10} \mathrm{~B}$ coated detectors as a function of film thickness $\left(D_{F}\right)$ with an $L L D$ setting of 300 $\mathrm{keV}$. The ${ }^{10} \mathrm{~B}$ film thickness required to achieve the maximum theoretical neutron detection efficiency (approximately $4 \%$ ) is only 2.4 microns. 


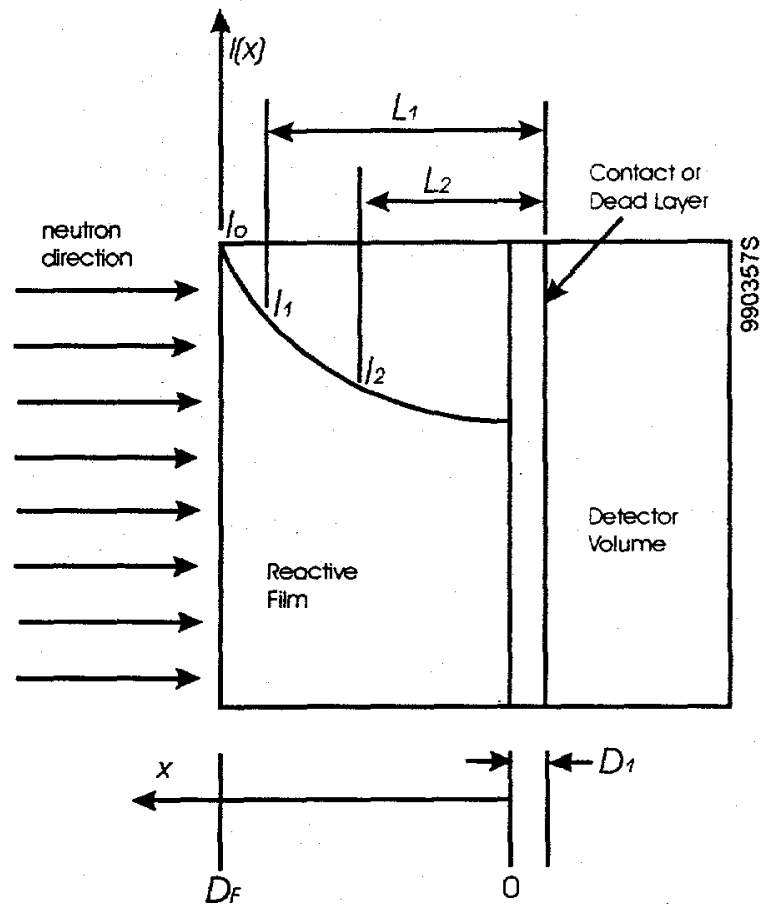

Figure 20 The thermal neutron flux will decrease as it becomes absorbed in the ${ }^{10} \mathrm{~B}$ film. Hence, the film thickness should not be deposited thicker than the maximum effective range of the reaction products.

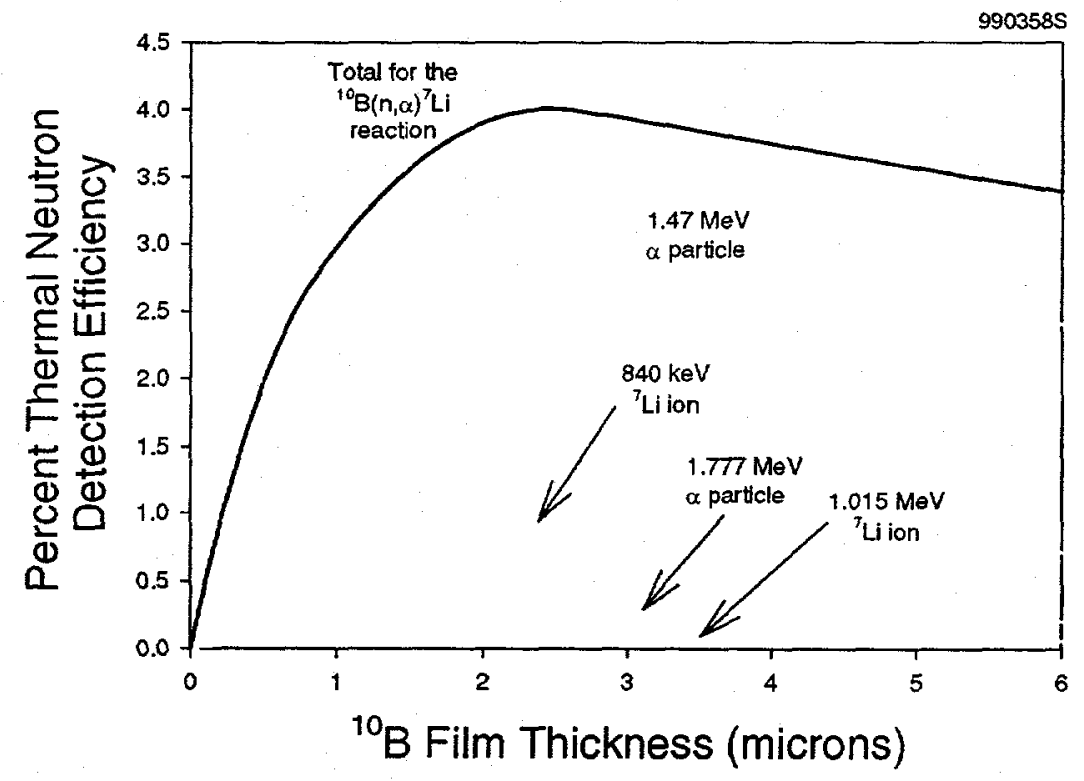

Figure 21 The calculated efficiency contributions of each reaction product particle and the total thermal neutron detection efficiency as a function of the ${ }^{10} \mathrm{~B}$ film thickness. 


\subsubsection{Neutron Beam Test Results}

The devices were operated in pulse mode for thermal neutron sensitivity testing. Individual devices were tested, in which each device was placed in a double diffracted thermal neutron beam from the Ford Nuclear Reactor. The double diffracted beam ensures that the device is tested with a low gamma ray background component. For testing, the devices were connected to a commercially available Ortec $142 \mathrm{~A}$ preamplifier. The testing configuration is shown in Figure 22.

The three main device configurations tested were:

- Device design M3-3242: a 2 micron thick active region GaAs diode with a $2000 \AA \mathrm{p}+\mathrm{GaAs}$ blocking contact. The devices were labeled S3242-\#.

- Device design M3-3243: a 5 micron thick active region GaAs diode with a $2000 \AA$ p + GaAs blocking contact. The devices were labeled S3243-\#.

- Device design M3-3278: a 5 micron thick active region GaAs diode with a thin Schottky blocking contact. The devices were labeled S3278-\#.

To test the devices, reverse bias was applied to determine the voltage limit. The p+ barrier devices, S3242 and S3243, withheld the highest voltage before breakdown, in some cases exceeding tens of volts. The Schottky barrier devices demonstrated breakdown at the lowest voltages, on the average at a reverse bias of 5 volts. Although the devices were tested with applied voltage, it was found that the built in potential of the blocking contact barrier was sufficient to operate the detectors. Hence, the devices can be operated without bias, a great advantage for detector array design and remote sensing applications.

The devices were placed in line with the neutron beam as shown in Figure 22. With the amplifier gain set at 300 , radiation induced signals were easily discernable on an oscilloscope. Tests were performed to determine the type of radiation causing the observable pulses. A $4 \mathrm{~mm}$ thick piece of lead was placed between the neutron beam collimator and the detector, in which no discernable change in the pulses could be observed. Afterwards, the lead was removed and a $1 \mathrm{~mm}$ thick piece of cadmium was placed between the neutron beam and the detector, upon which the signal pulses completely disappeared. Gamma rays are attenuated by lead, but neutrons are only slightly affected. However, cadmium has a large microscopic absorption cross section for thermal neutrons (20,000 barns), and efficiency blocks neutrons. Since the signal disappeared only when a neutron absorber was in the beam, and not when an efficient gamma ray absorber was in the beam, it was determined that all of the devices were indeed recording neutron interactions.

The calculated Bragg energy deposition curves for $\mathrm{p}+$ contact devices and the Schottky contact devices are shown in Figures 23 and 24, in which the reaction product particles enter the GaAs devices orthogonally. The individual detector zones in Figures 23 and 24 are clearly indicated. 


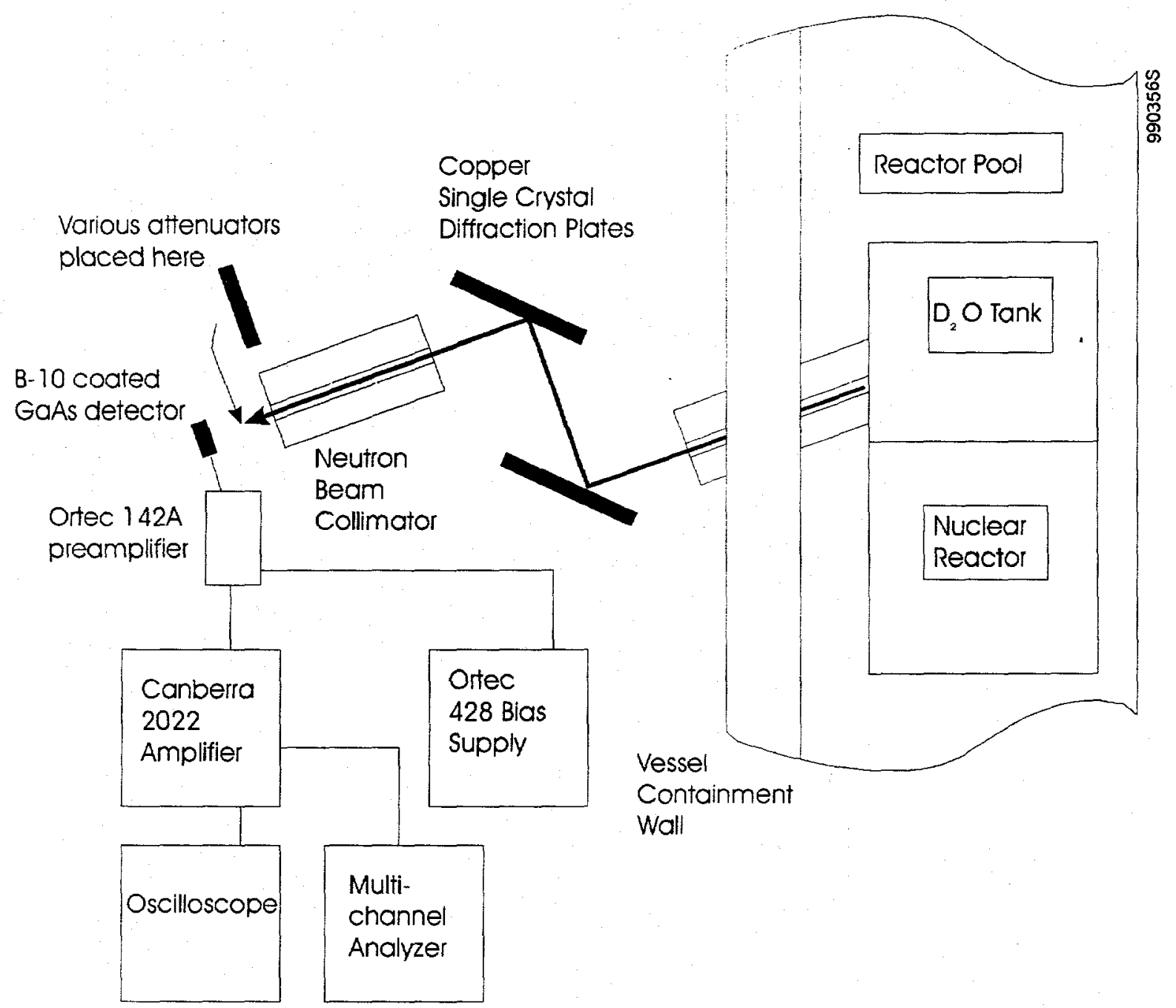

Figure 22 The experimental arrangement used to test the ${ }^{10} \mathrm{~B} / \mathrm{GaAs}$ detectors with thermal seutrons. Thermal neutrons from the Ford Nuclear Reactor are thermalized in a $\mathrm{D}_{2} \mathrm{O}$ tank. The neutrons are collimated and guided from the $\mathrm{D}_{2} \mathrm{O}$ tank to a work station, where they are double diffracted with single crystal copper plates. The neutron flux becomes smaller, yet the gamma ray component in the thermal neutron beam is significantly reduced. The neutron beam is then collimated through a $\mathbf{0 . 5}$ inch diameter high density polypropylene collimator to the work area. The ${ }^{10} \mathrm{~B} / \mathrm{GaAs}$ device is placed directly in the beam with ample space to insert different attenuators between the detector and the beam collimator. 
9903545

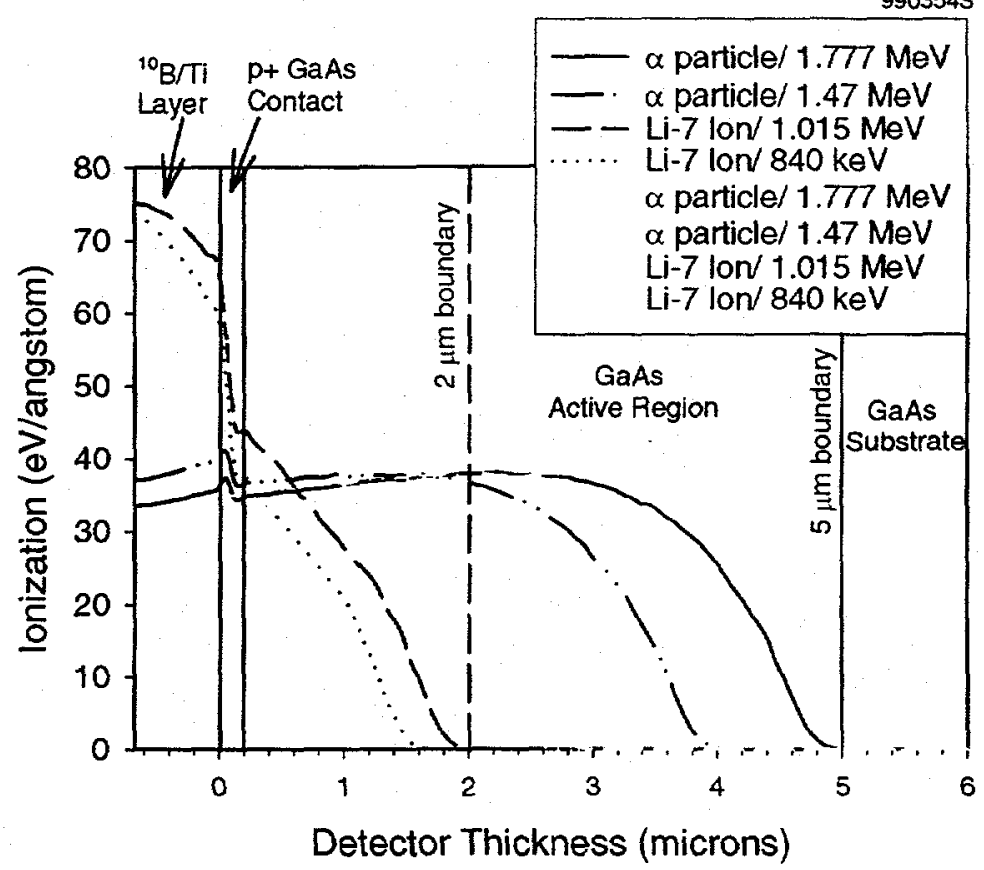

Figure 23 Bragg ionization distributions for charge particles transiting a ${ }^{10} \mathrm{~B} / \mathrm{GaAs}$ device with $6500 \mathrm{~A}$ of ${ }^{10} \mathrm{~B}$, and a $2000 \mathrm{~A} \mathrm{p}+\mathrm{GaAs}$ blocking contact layer. Interactions occurring at the contact are represented in gray, whereas interactions occurring at the surface of the ${ }^{10} \mathrm{~B}$ film are represented in black.

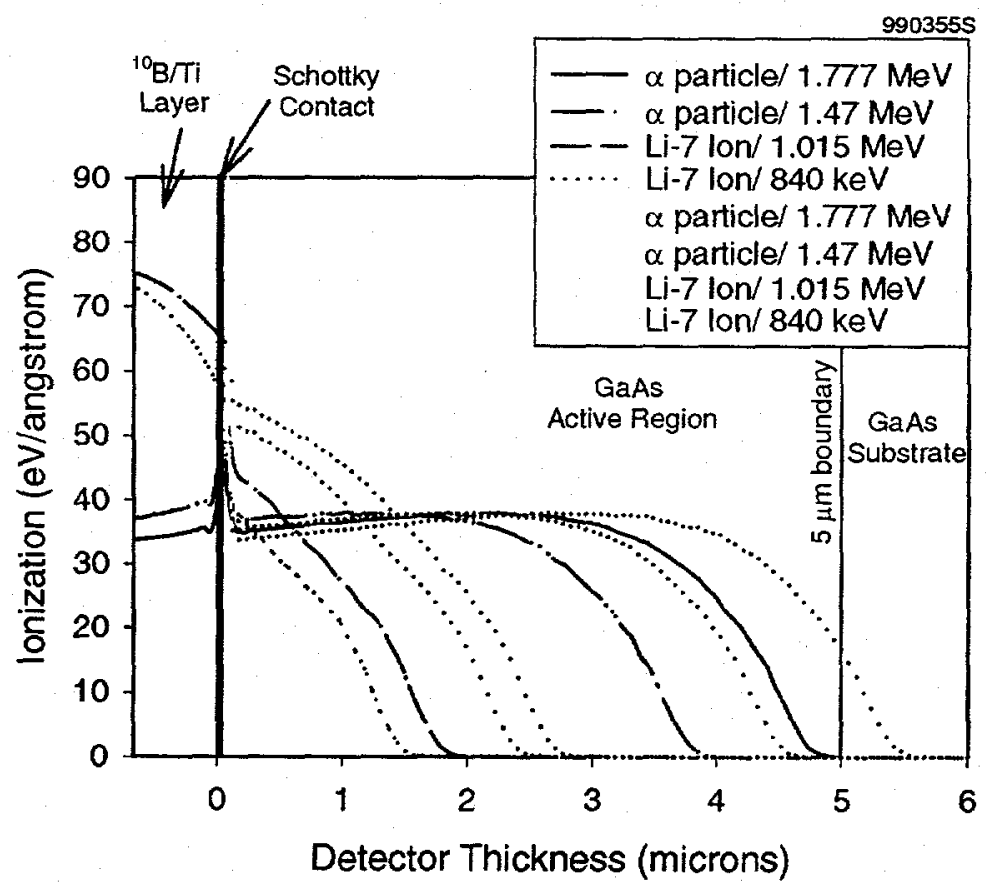

Figure 24 Bragg ionization distributions for charge particles transiting a ${ }^{10} \mathrm{~B} / \mathrm{GaAs}$ device with $6500 \AA$ of ${ }^{10} \mathrm{~B}$, and a thin Schottky contact layer. Interactions occurring at the contact are represented in gray, whereas interactions occurring at the surface of the ${ }^{10} \mathrm{~B}$ film are represented in black. 
Figures 25 through 27 show pulse height spectra taken from three different devices, those being S3242-3, S3243-1 and S3278-1. The spectral performance of the devices changed very little with applied voltage, and the spectra shown in Figures 25 through 27 are spectra with no voltage bias applied to the detectors. Each spectrum is different, giving indication of differences with the physical charge excitation and the collection process.

Figure 25 shows a spectrum acquired from S3242-3, which is a GaAs device with a 2 micron thick active region and a $2000 \AA \mathrm{p}+$ blocking contact. From Figure 23, both alpha particle and the $1.015 \mathrm{MeV}{ }^{7} \mathrm{Li}$ ion ranges extend beyond the active region thickness, and therefore, some of these particles' energies will be lost in the inactive GaAss substrate layer. From Figure 25 , a continuous spectrum is observed that extends up to approximately channel 600 . The pulse height spectrum is a consequence of several effects, those being particle energy selfabsorption in the ${ }^{10} \mathrm{~B}$ reactive layer, energy attenuation in the $\mathrm{p}+$ blocking contact layer, and incomplete energy deposition in the detector active region. Incomplete charge creation in the active region lowers the measured pulse height signal, which causes some of the electronic pulse signal to be covered by electronic noise. The observed peak is formed by superimposed energy deposition in the active region, that being the fact that the ${ }^{7} \mathrm{Li}$ ions and the alpha particles deposit, in many interactions, a similar amount of energy in the active region. Regardless, the total count rate was $21324+/-146$ per hour, yielding an estimated thermal neutron detection efficiency of approximately $1.7 \%+/-0.26 \%$.

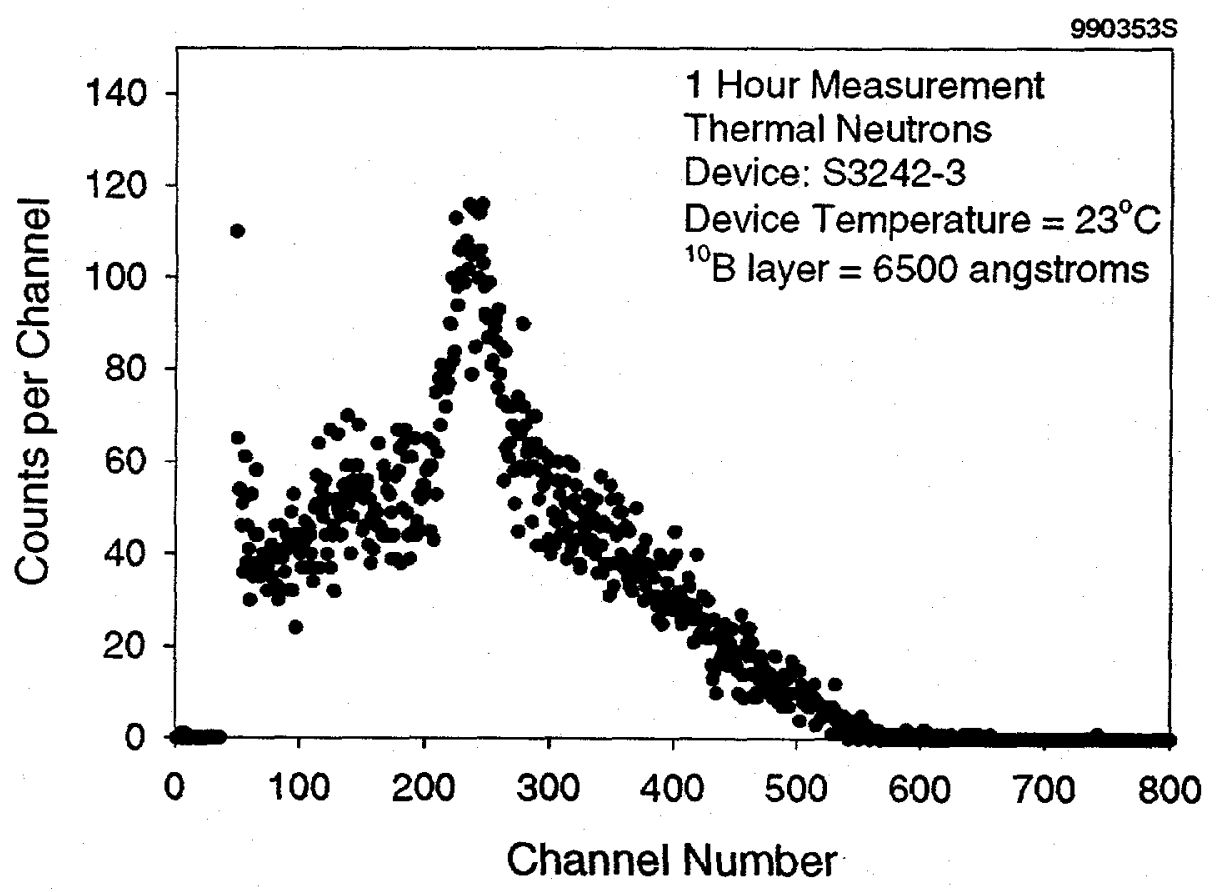

Figure 25 The reaction product spectrum from thermal neutron interactions in ${ }^{10} \mathrm{~B} / \mathrm{GaAs}$ detector \$3242-3. The thin active region ( 2 microns) is not large enough to absorb all of the energy from the alpha particles and the $1.015 \mathrm{MeV}{ }^{7} \mathrm{Li}$ ion, thereby yielding the continuous spectrum shown. The observed peak is an artifact of the incomplete energy deposition. 
Figure 26 shows a spectrum acquired from S3243-1, which is a GaAs device with a 5 micron thick active region and a $2000 \AA \mathrm{p}+$ blocking contact. From Figure 25 , in it is clear that the GaAs active layer is thick enough to absorb most of the energy from the reaction products that enter the device. Only the $1.777 \mathrm{MeV}$ alpha particle range can extend slightly beyond the 5 micron active region depth. Since the $1.777 \mathrm{MeV}$ alpha particle has a branching ratio of only $6 \%$, the energy lost is minimal. The spectrum shown in Figure 26 is for the "no bias" condition, in which no external operating voltage was necessary. Different than the performance of S3242-3, the device shows larger pulse height signals, in which the spectrum extends up to channel 700 . Clearly shown are events attributable to the $1.777 \mathrm{MeV}$ alpha particle (6\% branching ratio), the 1.47 $\mathrm{MeV}$ alpha particle (branching ratio 94\%), and the combined contributions of the $1.015 \mathrm{MeV}$ $(6 \%)$ and $840 \mathrm{keV}(94 \%){ }^{7} \mathrm{Li}$ ions. The total count rate was $27743+/-167$ per hour, yielding an estimated thermal neutron detection efficiency of approximately $2 \%+/-0.3 \%$.

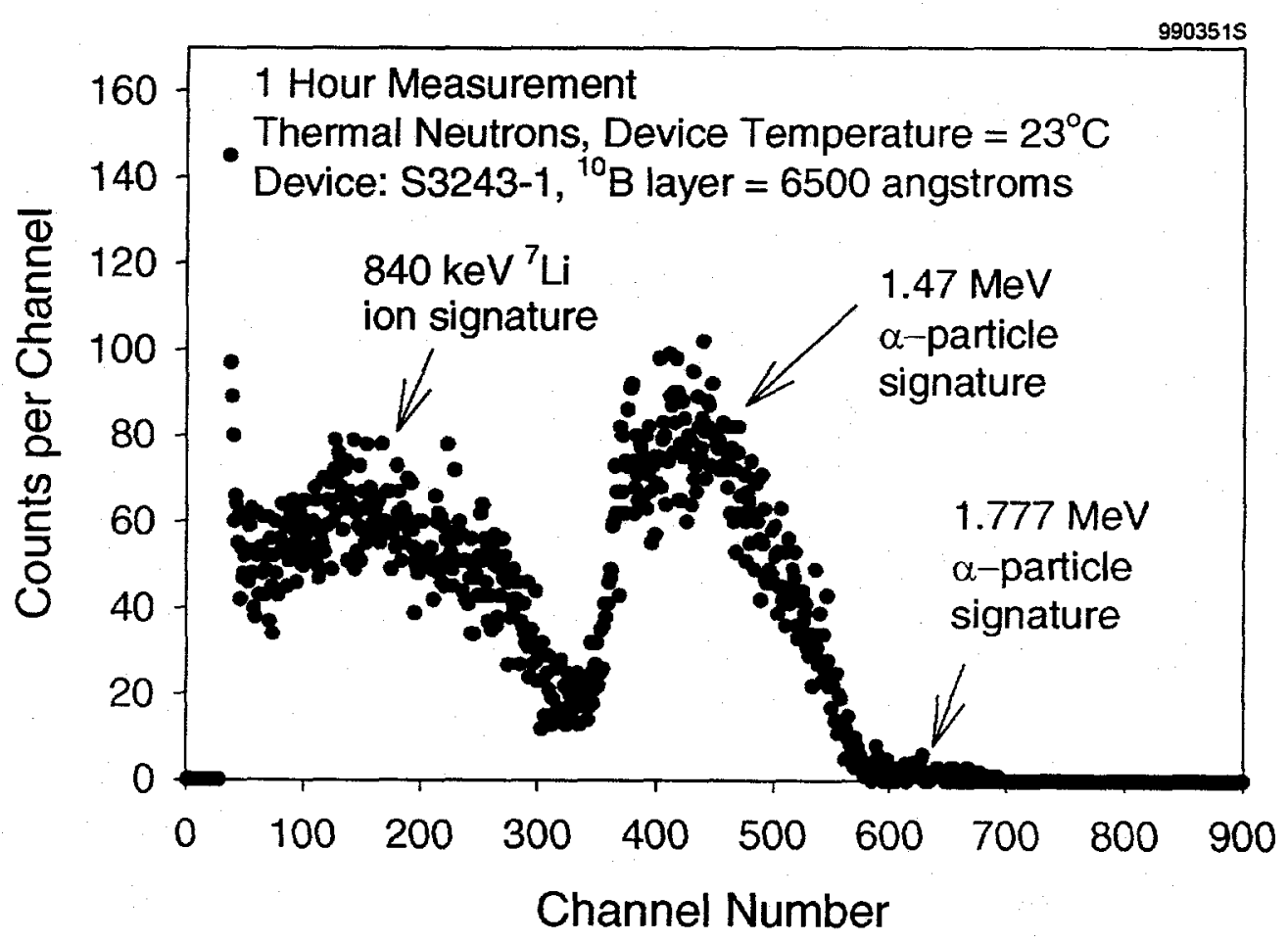

Figure 26 The reaction product spectrum from thermal neutron interactions in ${ }^{10} \mathrm{~B} / \mathrm{GaAs}$ detector \$3243-1. The 5 micron active region is large enough to absorb all particle energies, except for some from the $1.777 \mathrm{MeV}$ alpha particle. As a result, the different charged particle contributions are apparent in the pulse height spectrum.

Figure 27 shows a spectrum acquired from S3278-1, which is a GaAs device with a 5 micron thick active region and a thin Schottky barrier blocking contact. Figure 24 shows the Bragg distribution curves for reaction product charged particles orthogonally entering the detector, again showing that only the $1.777 \mathrm{MeV}$ alpha particle range can extend slightly beyond the 5 micron active region depth. The spectrum shown in Figure 27 is for the "no bias" condition, in which no external operating voltage was necessary. Similar to S3243-1, clearly shown are events attributable to the $1.777 \mathrm{MeV}$ alpha particle (6\% branching ratio), the $1.47 \mathrm{MeV}$ alpha 
particle (branching ratio 94\%), and the combined contributions of the $1.015 \mathrm{MeV}(6 \%)$ and 840 $\mathrm{keV}(94 \%){ }^{7} \mathrm{Li}$ ions. The charged particle energy resolution is slightly better than observed with S3243-1, which may be due to less energy loss in the thinner Schottky contact layer. The total count rate was $23512+/-153$ per hour, yielding an estimated thermal neutron detection efficiency of approximately $2 \%+/-0.3 \%$.

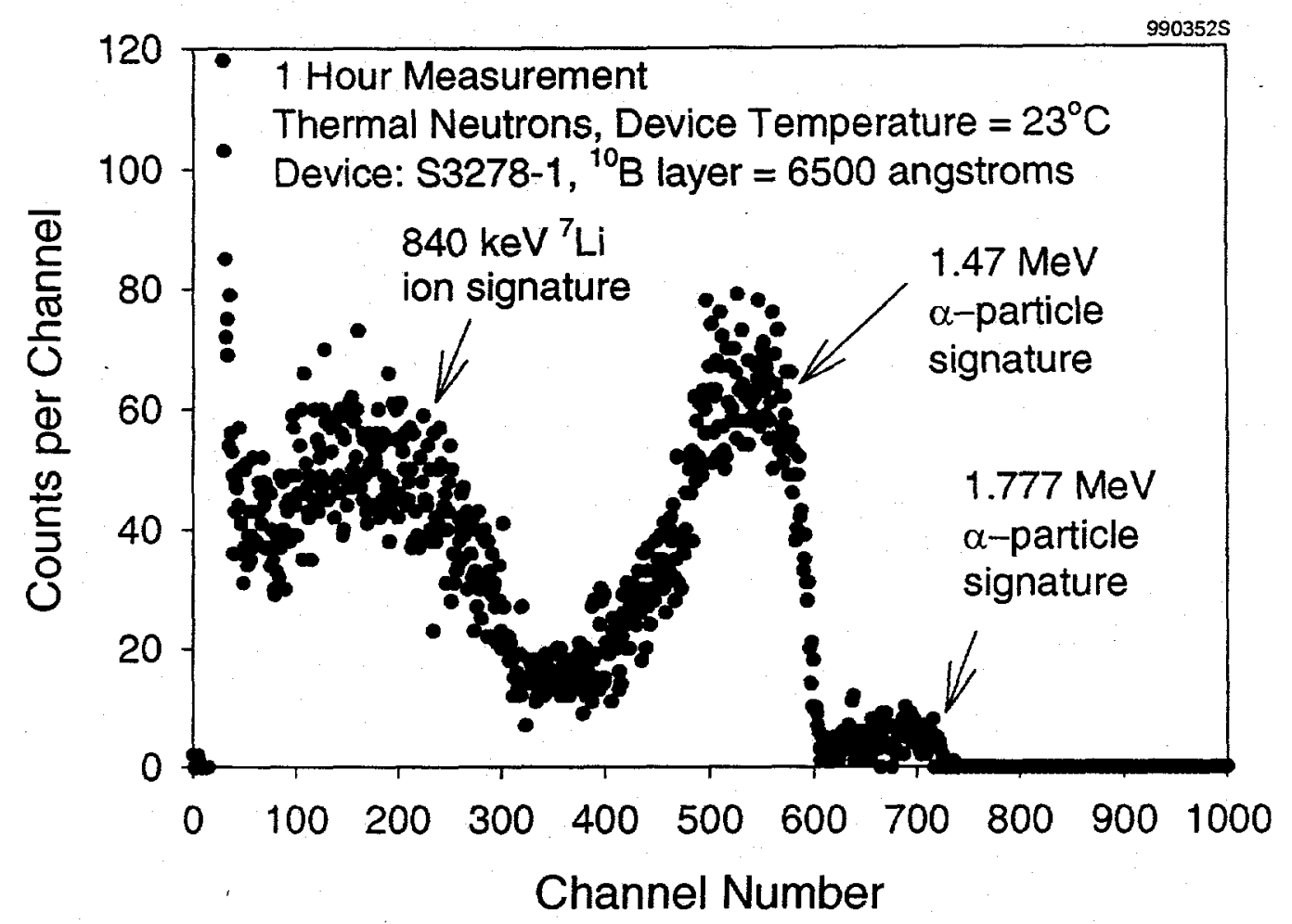

Figure 27 The reaction product spectrum from thermal neutron interactions in ${ }^{10} \mathrm{~B} / \mathrm{GaAs}$ detector \$3278-1. The 5 micron active region is large enough to absorb all particle energies, except for some from the $1.777 \mathrm{MeV}$ alpha particle, and the different charged particle contributions are apparent in the pulse height spectrum. The higher energy resolution observed than the $p+$ contact devices may be due to lower charged particle energy loss in the thin Schottky barrier contact.

Overall, the results shown are representative of the devices tested, in which case the devices fabricated across each wafer were fairly uniform in performance. Hence, production of array scale devices should be straightforward and achievable. Both the Schottky contact design and the $\mathrm{p}+$ contact design show promise, with a note that the GaAs device active region should be increased to at least 5.5 microns thick to absorb all of the reaction product energies. Ultimately, the ${ }^{10} \mathrm{~B}$ film should be increased to the optimum thickness, being 2.4 microns for a device operated with a lower level discriminator $(L L D)$ setting of $300 \mathrm{keV}$. The $L L D$ setting of $300 \mathrm{keV}$ allows for high confidence in gamma ray background rejection in a mixed radiation field of gamma rays and thermal neutrons, an environment generally found in thermal neutron radiography applications.

The $\mathrm{p}+$ contact GaAs devices with 2 micron thick active regions demonstrated slightly lower thermal neutron detection efficiency than previously demonstrated by Schottky barrier bulk GaAs devices.' The reason for the lower efficiency is clearly due to incomplete energy 
deposition in the detector active region. The $\mathrm{p}+$ contact and Schottky contact GaAs devices with 5 micron thick active regions compared well with previous results, ${ }^{9}$ with the Schottky contact devices demonstrating the least amount of energy loss in the contact region. Although all of the devices operated well without bias voltage, the p+ contact GaAs devices withstood higher applied voltages than the Schottky contact devices. Furthermore, the p+ contact GaAs devices demonstrated lower noise characteristics than the Schottky barrier devices.

\section{SUMMARY}

Epitaxially grown GaAs PIN diode have been shown to be quite useful in neutron detection applications. The PIN structure has been shown to be superior to a Schottky barrier design, and use of an $\mathrm{Al}_{\mathrm{x}} \mathrm{Ga}_{1-\mathrm{x}}$ As BSF has been seen to lead to increased efficiency when tested with $5.5 \mathrm{MeV}$ alpha particles. Growth by MOCVD has resulted in very-low carrier concentration GaAs active layers with good electron-hole-collection properties. GaAs diodes have shown currents as high as $9.78 \times 10^{-7} \mathrm{~A} \mathrm{~cm}^{-2}$ when irradiated by alpha particles. Response to neutrons was tested at University of Michigan and shown to be excellent. Detection efficiency was $2.0 \%$ for these "first-try" PIN diodes, slightly better than the $1.8 \%$ previously measured for Schottky barrier GaAs devices from that laboratory. ${ }^{9}$ No externally applied biases were needed. Device performance across a wafer was very uniform, indicating that multi-element array production will be straightforward. PIN diodes also showed higher breakdown voltages and lower noise characteristics than the Schottky devices.

\section{ACKNOWLEDGEMENTS}

The growth of diodes by MOCVD was carefully performed by Mssrs. S. Markham and R. Cunha, with valuable advice from Mr. V. Haven; material characterization was done at Spire by Ms. C. Reader and C. Muldoon; device testing at Spire was carefully carried out by Dr. W. Neal and Ms. C. Stenstrom; device processing was handled by Mr. D. Taylor. Lifetime measurements were provided courtesy of Drs. R. Ahrenkiel and B. Keyes at NREL. The input of Dr. S. Wojtczuk at Spire on device and processing issues is greatly appreciated. Thanks are due to Dr. D. McGregor at University of Michigan for help in designing the devices, completing fabrication with boron, and testing for response to neutrons.

\section{PHASE II PLANS}

Phase II will concentrate on optimizing the diodes developed here and on developing an array technology to use in radiography applications. Particular attention will be paid to optimizing the BSF structure, since that has shown great promise.
7 REFERENCES
1. D.S. McGregor, G.F. Knoll, Y. Eisen, and R. Brake, IEEE Trans. Nucl. Sci., NS-39, 1226 (1992);
2. D.S, McGregor, .A. Rojeski, G.F. Knoll, F.L. Terry, Jr., J. East, and Y. Eisen, J. Appl. Phys., $\underline{75}, 7910$ (1994);
3. M. Alietti, C. Canali, A. Castaldini, A. Cavellini, A. Cetronio, C. Chiossi, S. D'Auria, C. del Papa, C. Lanzieri, F. Nava, and P. Vanni, Nucl. Instr, and Meth., A362, 344 (1995)
4. G.F. Knoll, Radiation Detection and Measurement, 2nd Ed.(Wiley, New York, 1989). 
5. V. McLane, C.L. Dunford and P.F. Rose, Neutron Cross Sections, Vol. 2 (Academic Press, San Diego, 1988).

6. R.D. Evans, The Atomic Nucleus (McGraw-Hill, New York, 1955).

7. I. Kaplan, Nuclear Physics, 2nd Ed. (Addison-Wesley, Reading, 1962).

8. J.F. Ziegler and J.P. Biersack, SRIM-2000 Code, Version 9 (IBM Company, 1998).

9. D.S. McGregor, J.T. Lindsay, C.C. Brannon and R.W. Olsen, "Semi-Insulating GaAs Thermal Neutron Imaging Arrays," IEEE Trans. Nucl. Sci., Vol. 43, (1996) pp. 13571364. 